\title{
Near-term regional climate change over Bangladesh
}

\author{
Yeon-Woo Choi ${ }^{1}$ (1) Deborah J. Campbell ${ }^{2} \cdot$ John C. Aldridge ${ }^{2} \cdot$ Elfatih A. B. Eltahir $^{1}$
}

Received: 20 January 2021 / Accepted: 17 June 2021 / Published online: 5 July 2021

(c) The Author(s) 2021

\begin{abstract}
Bangladesh stands out as a climate change hot spot due to its unique geography, climate, high population density, and limited adaptation capacity. Mounting evidence suggests that the country is already suffering from the effects of climate change which may get worse without aggressive action. Here, we use an ensemble of high-resolution $(10 \mathrm{~km})$ regional climate model simulations to project near-term change in climate extremes, mainly heat waves and intense rainfall, for the period (2021-2050). Near-term climate projections represent a valuable input for designing sound adaptation policies. Our climate projections suggest that heatwaves will become more frequent and severe in Bangladesh under the business-as-usual scenario (RCP8.5). In particular, extremes of wet-bulb temperature (a temperature and humidity metric important in evaluating humid heat stress) in the western part of Bangladesh including Bogra, Ishurdi, and Jessore are likely to exceed the extreme danger threshold (according to U.S. National Weather Service criterion), which has rarely been observed in the current climate. The return periods of extreme heat waves are also significantly shortened across the country. In addition, country-averaged rainfall is projected to increase by about $6 \%$ during the summer months, with the largest increases (above 10\%) in the eastern mountainous areas, such as Sylhet and Chittagong. Meanwhile, insignificant changes in extreme rainfall are simulated. Our results suggest that Bangladesh is particularly susceptible to climate extremes in the near future, in the form of extreme heat waves over the western part of the country.
\end{abstract}

Keywords Regional climate model $\cdot$ Dynamical downscaling $\cdot$ Fine-scale climate projections $\cdot$ Extreme precipitation $\cdot$ Heat stress

\section{Introduction}

Scientific evidence has shown that rising anthropogenic greenhouse gas (GHG) concentrations due to human activity are unequivocally accelerating global warming (IPCC 2013). As global warming steadily progresses since the industrial revolution, weather-related extremes, like heat waves and intense rainfall, are increasing in likelihood, threatening human life and causing socio-economic damage worldwide (Meehl and Tebaldi 2004; Kharin et al. 2013; Sillmann et al. 2013). Developing and financially challenged countries are especially vulnerable to the impacts of climate change due to their limited resources and low adaptive capacity, and some

Yeon-Woo Choi

choiyw@mit.edu

1 Ralph M. Parsons Laboratory, Massachusetts Institute of Technology, Cambridge, MA 02139, USA

2 Lincoln Laboratory, Massachusetts Institute of Technology, Cambridge, USA of these countries are already facing a climate crisis (Huq 2001; Kreft et al. 2017). Therefore, it is critical to project the impacts of near-term climate change in the most vulnerable regions, such as Bangladesh (Huq 2001; Kreft et al. 2017), in order to inform sound adaptation strategies.

Bangladesh, one of the world's most impoverished countries, stands out as a climate change hot spot because of its weak infrastructure, geographic conditions and dense population (more than 1100 inhabitants per square kilometer shown in Fig. 1; Huq 2001; World Bank 2013; Kreft et al. 2017). The climate in Bangladesh is typically humid due to its proximity to the Bay of Bengal, and hence is prone to the impacts of extreme weather events including heat stress and heavy rainfall (Khan et al. 2000; Shahid 2010, 2011; Shahid et al. 2016). Since the country belongs to the Asian monsoon regime, predominant southerly flows during summer monsoon season can further worsen the risk of heat stress by transporting warm and moist air masses from the Bay of Bengal to Bangladesh (Shahid et al. 2016). Given the aforementioned factors, the country is particularly vulnerable to 
(a)

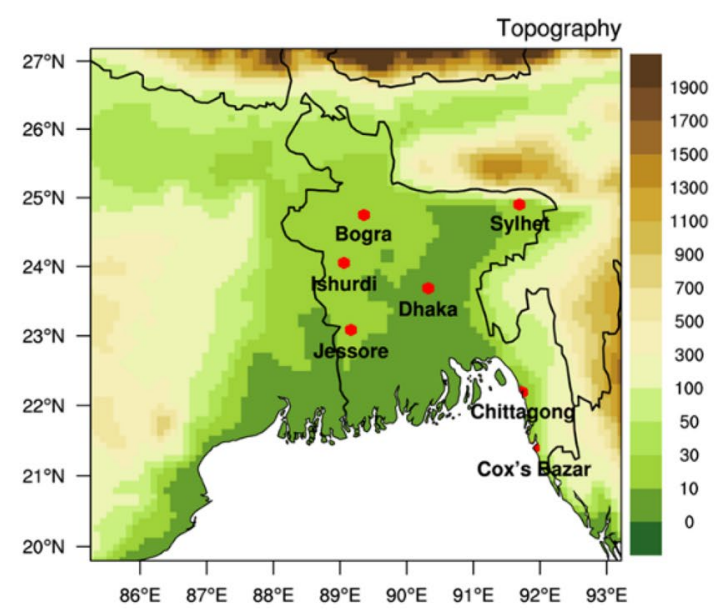

(b)

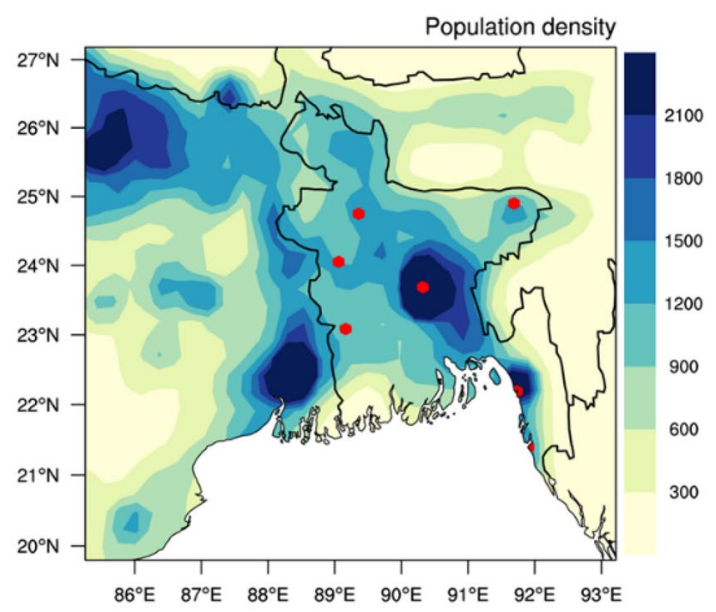

(c)

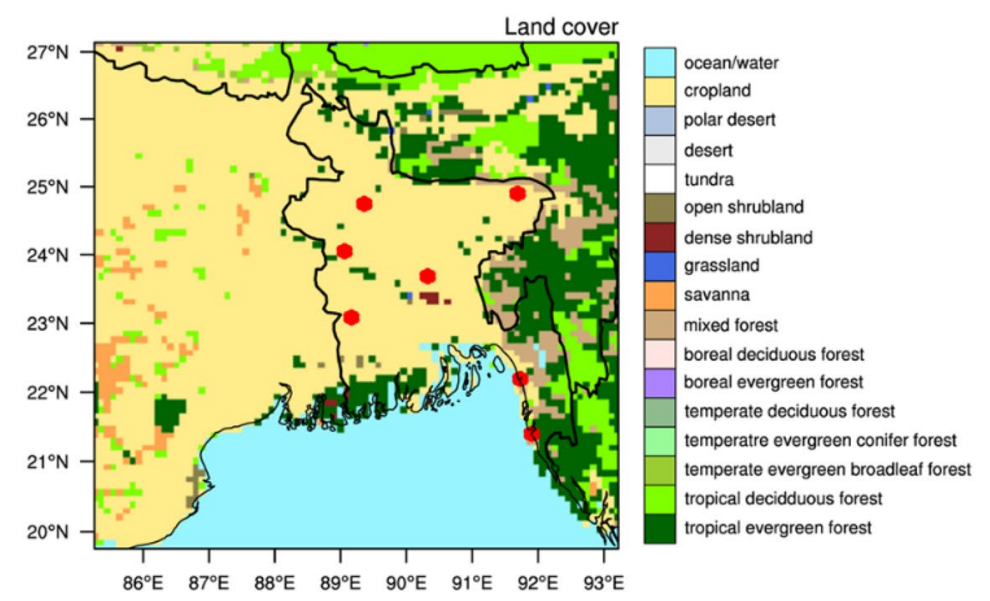

Fig. 1 MRCM simulation domain. a Topography (unit: m), b population density (unit: persons per square kilometre; CIESIN, 2018) and c MRCM land cover. The red dots denote the location of 7 weather stations over Bangladesh

the impacts of climate change, and the risks associated with these impacts will likely be exacerbated as climate change becomes more pronounced (Huq 2001).

As exemplified by recent climate records, heat and rainfall extremes are already deadly in Bangladesh. According to modern record (1979-2015), record-shattering heat waves impacted South Asian countries (e.g., India, Pakistan and Bangladesh) along the Indus and Ganges river valleys (Im et al. 2017a; Raymond et al. 2020). Recently, a maximum wet-bulb temperature above $31{ }^{\circ} \mathrm{C}$ was recorded in Bangladesh, which is extremely dangerous for human health (Im et al. 2017a, 2018; Kang et al. 2019b; Sherwood and Huber 2010; Raymond et al. 2020). The 2015 South Asian heat wave was estimated to have caused 4,000 deaths as a consequence of heat-related diseases (UN ESCAP 2015; Ghumman and Horney 2016; Zommers et al. 2016). In addition to temperature extremes, devastating floods resulted in a death toll over 1,000 and affected an estimated 40 million people over South Asia in 2017 (Gettleman 2017). Bangladesh is frequently threatened by devastating cyclones with intense rainfall every three years on average (MoEF 2009). Without serious mitigation measures, Bangladesh will face an increasing risk of more severe impacts in the coming decades.

Based on future climate projections using General Circulation Models (GCMs), southwest Asian countries are likely to be exposed to deadly weather extremes including heat waves and extreme heavy rainfall in the future (OECD 2003; May 2004; Sillmann et al. 2013; Kirtman et al. 2013; Coffel et al. 2018). Since the vulnerability to climate extremes is largely dependent on geographical location and topographical characteristics, GCMs with coarse resolution and inadequate representation of physical processes have limitations in simulating the fine scale climate extremes (Seneviratne 
2012; Flato et al. 2013; Im et al. 2017b). Dynamically downscaled simulations using a regional climate model facilitate in-depth analysis of extremes over Bangladesh. Most previous regional climate modeling studies were confined to the far future period ( $\mathrm{Gu}$ et al. 2012; Im et al. 2017a) close to the end of the century (2071-2100), and have analyzed the likelihood of extremes based on maximum temperature (e.g., Gu et al. 2012).

In our earlier study by Im et al. (2017a), we projected changes in wet-bulb temperature over south Asia towards the end of the century using a regional climate model at $25-\mathrm{km}$ resolution. In this study, we investigate the changes in extreme heat stress and rainfall in response to the business-as-usual near-term climate change scenario based on ensemble of projections using the high-resolution $(10 \mathrm{~km})$ MIT Regional Climate Model (MRCM), allowing a more detailed representation of topography, coastlines, physical processes, and extreme climatic events.

\section{Regional climate model and experimental setup}

\subsection{Regional climate model description}

The MRCM is a three-dimensional hydrostatic numerical model, which was developed at MIT to understand how global climate and land-use changes may impact society (e.g., Im et al. 2017a). The general structure and dynamical core of the MRCM originate from the Abdus Salam International Centre for Theoretical Physics (ICTP) Regional Climate Model version 3 (RegCM3; Pal et al. 2007). Characteristically, the Integrated Biosphere Simulator (IBIS; Foley et al. 1996) is coupled to the MRCM to obtain better representation of land surface processes (Winter et al. 2009). In addition to coupling with the IBIS, the MRCM notably employs several improvements of model physics, such as a new surface albedo assignment (Marcella 2012; Marcella and Eltahir 2012), an irrigation scheme (Marcella 2012; Marcella and Eltahir 2014), a new convective cloud, and rainfall autoconversion schemes (Gianotti 2012; Gianotti and Eltahir 2014a, 2014b), and a modified boundary layer height and boundary layer cloud scheme (Gianotti 2012).

The MRCM has been extensively evaluated in its ability to simulate the fine-scale structure of climatic variables over various domains, such as North America (Winter et al. 2009), West Africa (Im et al. 2014), Southwest Asia (Pal and Eltahir 2016), South Asia (Im et al. 2017a), and the Maritime Continent (Im and Eltahir 2018). Pal and Eltahir (2016) have improved the capability of the MRCM through prescribing the satellite-derived albedo and adjusting the associated parameters. They showed that the upgraded version of MRCM captured the key observed climate features over the desert and semi-desert region, particularly Southwest Asia. Im et al. (2017a) showed that the MRCM could suitably reproduce the spatial pattern and magnitude of temperature fields (e.g., dry-bulb and wet-bulb temperatures) over the South Asia region. Given the satisfactory performance of the model in this recent study over South Asia, the MRCM is applied in this study to simulate regional climate over Bangladesh.

\subsection{Optimization of the model parameters}

Despite various updates and improvements of the MRCM, the latest version of the MRCM with default settings still has limitations in reproducing region-specific climate information. Thus, it is necessary to optimize the model performance for the current domain before projecting future climate. Several parameters in the cloud microphysics and convection schemes are updated bringing them close to the values recommended in recent version of RegCM version 4 (Giorgi et al. 2016): (1) The auto-conversion rate is $0.50 \times 10^{-3} \mathrm{~s}^{-1}$; (2) accretion rate is $6 \mathrm{~m}^{3} \mathrm{~kg}^{-1} \mathrm{~s}^{-1}$; (3) raindrop evaporation rate is $1.0 \times 10^{-5}\left(\mathrm{kgm}^{-2} \mathrm{~s}^{-1}\right)^{-1 / 2} \mathrm{~s}^{-1}$; (4) maximum negative parcel temperature perturbation is $0.9 \mathrm{~K}$; and (5) approach rate to quasi-equilibrium is $0.2 \mathrm{kgm}^{-2} \mathrm{~K}^{-1} \mathrm{~s}^{-1}$. Furthermore, we adjusted the parameters of cloud liquid water based on the study of Im and Eltahir (2018): (6) climatological cloud liquid water in continental and maritime environments are set to $1.0 \mathrm{~g} \mathrm{~m}^{-3}$ and $0.4 \mathrm{~g} \mathrm{~m}^{-3}$, respectively; (7) Threshold of cloud liquid water is $1.1 \mathrm{~g} \mathrm{~m}^{-3}$ in continent, and $0.45 \mathrm{~g} \mathrm{~m}^{-3}$ in maritime.

\subsection{Experimental design}

The simulation domain covers South Asia centered in Bangladesh with a horizontal resolution of $10 \mathrm{~km}$ on a Lambert conformal projection (Fig. 1). It consists of $84 \times 81 \times 18$ grid points along the zonal, meridional, and vertical (sigma coordinate) directions, respectively. To minimize interference from the elevated topography located in the vicinity of the lateral boundary zone, we choose the slightly larger domain which fully covers Bangladesh as well as the surrounding mountainous area. We use this setup for evaluation runs and climate simulations.

Before applying the regional climate modeling system to project future climate, it is important to assess the capability of the model in reproducing the present climate conditions in terms of the spatial distribution as well as the seasonal cycle of climatic variables (i.e., temperature and precipitation) to identify possible systematic biases, present in the model. In this regard, we conducted an evaluation run (i.e., known as perfect boundary simulation) using the MRCM driven by 6-hourly European Centre for Medium-Range Weather Forecasts (ECMWF) Interim Re-Analysis (ERA-Interim) 
with a resolution of $1.5^{\circ}$ (Uppala et al. 2008). The $1^{\circ} \times 1^{\circ}$ weekly NOAA Optimum Interpolation Sea Surface Temperature (OISST) v2 data (Reynolds 2002) is prescribed as the lower boundary condition of the MRCM. The simulation period of evaluation run is from 1982 to 2012, because NOAA OISST data (i.e., sea surface boundary condition) is available from 1982, and at least a 30 -year simulation is required for climate study.

To test the necessity of 10-km high-resolution simulation over Bangladesh where the topography is almost flat with an elevation of less than $50 \mathrm{~m}$, we additionally conducted low-resolution $(30 \mathrm{~km})$ MRCM simulation for the 10-year period (1983-1992) using the same model configuration (e.g., physics scheme, boundary condition from the ERAInterim reanalysis). By comparison with the low-resolution result, 10-km MRCM simulation can provide added value by better representing spatial distribution of temperature and precipitation particularly along the coastal and eastern mountainous regions (Suppl. Figure 1). This result is consistent with recent studies that demonstrated the advantages of high-resolution simulations (Ciarlo et al., 2020; Qiu et al., 2020).

Through a rigorous screening process, Im et al. (2017a) recommended three Coupled Model Inter-comparison Project Phase 5 (CMIP5) GCMs [Community Climate System Model Version 4 (CCSM), Australian Community Climate and Earth System Simulator Version 1.0 (ACCESS), and Max-Planck-Institution Earth System Model running on Medium Resolution grid (MPI)] to use as lateral boundary conditions of the MRCM climate simulation over South Asia. They found that the MRCM simulations driven by these GCMs are able to capture local climate characteristics (e.g., seasonal mean climatology and extreme temperatures) of South Asia. In accordance with this recommendation, the same three GCMs are selected in this study as driving boundary conditions for the MRCM to project future climate change and its impacts. The general information describing these CMIP5 models is summarized in Table 1. We performed three reference simulations for the period 1975-2005 with the historical greenhouse gas (GHG) concentration and conducted three time-slice simulations under the businessas-usual anthropogenic emissions scenario, namely, RCP8.5, for the period 2020-2050. The first year of each simulation is regarded as the spin up period, and thus are not considered in the analysis. We assumed that the skill of the model under current and future climate conditions is the same (Suh et al. 2016).

\subsection{Bias correction}

All simulations by a regional climate model suffer from systematic bias arising from lateral boundary conditions and their imperfect dynamics and physical processes (Liang et al. 2008; Ehret et al. 2012). In order to reduce the aforementioned bias, we applied the Parametric Quantile Mapping (PQM) technique. This method is commonly used in climate change studies to correct for the structural biases in the rainfall and temperature fields although several problematic aspects are possible: parametric quantile mapping may artificially corrupt the modeled climate change signals (Cannon et al., 2015; Switanek et al., 2017). High-resolution Terraclimate data (horizontal resolution is about $4 \mathrm{~km}$; Abatzoglou et al. 2018) is used to correct for biases in drybulb temperature and precipitation in the model output, and ERA-interim is used to correct the bias of wet-bulb temperature for the entire domain at the monthly time scale. Also, weather observations at 7 major cities (Fig. 1; Dhaka, Jessore, Bogra, Sylhet, Ishurdi, Chittagong, and Cox's Bazar) in Bangladesh are applied to correct the mean biases of MRCM simulations at daily time scale. To calculate the daily maximum wet-bulb temperature at stations, daily minimum relative humidity is estimated using the following formulation (Allen et al. 1998).

$R H_{\min }=\frac{e_{a}}{e_{s}\left(T_{\max }\right)} \times 100$

where $\mathrm{RH}_{\min }$ is the daily minimum relative humidity, $\mathrm{T}_{\max }$ the daily maximum temperature, $\mathrm{e}_{\mathrm{a}}$ the actual vapor pressure of air, $\mathrm{e}_{\mathrm{s}}\left(\mathrm{T}_{\max }\right)$ saturated vapor pressure of air at maximum temperature. For bias correction, we specifically applied the method following Piani et al. (2010) and Kang et al. (2019a, 2019b). The first step in the PQM is to calculate the cumulative frequency distributions of the modeled and

Table 1 Descriptions of CMIP5 GCMs used as initial and lateral boundary condition of MRCM

\begin{tabular}{|c|c|c|c|}
\hline Model & Institute & Atmosphere & Ocean \\
\hline $\begin{array}{l}\text { Community Climate System Model version } 4 \\
\text { (CCSM4) }\end{array}$ & National Center for Atmospheric Research (NCAR) & $0.9^{\circ} \times 1.25^{\circ}$ & $1.11^{\circ} \times 0.27^{\circ}-0.54^{\circ}$ \\
\hline $\begin{array}{l}\text { Max Planck Institute Earth System Model, mixed } \\
\text { resolution (MPI-ESM-MR) }\end{array}$ & Max Planck Institute for Meteorology (MPI-M) & $\mathrm{T} 63\left(\sim 1.875^{\circ}\right)$ & $0.4^{\circ} \times 0.4^{\circ}$ \\
\hline $\begin{array}{l}\text { Australian Community Climate and Earth System } \\
\text { Simulator version 1.0 (ACCESS 1.0) }\end{array}$ & $\begin{array}{l}\text { Commonwealth Scientific and Industrial Research } \\
\text { Organization (CSIRO), the Bureau of Meteorol- } \\
\text { ogy }\end{array}$ & $1.25^{\circ} \times 1.875^{\circ}$ & $1 / 3^{\circ}-1^{\circ}$ \\
\hline
\end{tabular}


observed climatic variables (i.e., rainfall, dry-bulb and wetbulb temperatures) for each month with the assumption that temperatures and rainfall distributions are well approximated by the gaussian and gamma distributions, respectively. The modeled cumulative frequency distribution for the variable of interest, simulated for the past, is then corrected to fit the observed distribution. The same correction factors are then applied to correct the bias in the simulated future variable considered.

\section{Results}

\subsection{Evaluation of "perfect boundary" simulation}

We assume that the MRCM has sufficient skill for use in this study to project climate change over Bangladesh based on comparison with temperature and rainfall observations (Figs. 2 and 3). Figure 2 shows the observed and simulated seasonal climatology of temperature over Bangladesh during the reference period (1983-2012). The MRCM adequately reproduces the mean surface temperature distribution over the target region in all seasons, as compared with the corresponding observations. For pre-monsoon season (March, April, May (MAM)), the mean temperature shows a distinct gradient from Southwest to Northeast, warmest in Southwest coastal region and coolest near the Northeast mountainous area. Meanwhile, a south to north gradient is evident across the region in winter. The observed temperatures are high from monsoon to post-monsoon seasons, decreasing markedly as winter approaches. All these features are well captured by the MRCM, although a cold bias exists in certain seasons. During post-monsoon season, the model shows a noticeable cold bias of up to $2-3^{\circ} \mathrm{C}$ over most of the region. This systematic discrepancy has also been reported by previous studies (e.g., Rahman et al. 2012).

The MRCM reasonably reproduces the seasonal variation of rainfall over Bangladesh as compared to TerraClimate observation. Figure 3 presents seasonal mean rainfall derived from TerraClimate observation and MRCM simulation. The observed rainfall exhibits a west-east gradient, and it peaks in monsoon season with more than $60 \%$ of the total annual rainfall in Bangladesh. According to the geographical setting, high rainfall is observed along the high mountainous regions, and relatively dry conditions are observed in the low-lying plain regions. These features are well captured by high-resolution MRCM simulation, although it suffers from some systematic biases across the region. The MRCM tends to underestimate mean rainfall, especially in the low elevation regions during monsoon and post-monsoon seasons, meanwhile it shows a large overestimation of mean rainfall along the northeastern parts of Bangladesh for premonsoon and monsoon seasons. The magnitude of the bias is comparatively higher in the mountainous regions. Some of these biases are expected due to the difficulty representing dynamics over mountainous regions with sharp elevation gradients, in regional climate models (Im and Eltahir 2018).

\subsection{Evaluation of reference simulation}

As discussed in the previous sections, the MRCM has been tested in several climate change studies. The next steps in testing the reliability of future projections is to identify systematic errors apparent in historical climate simulations (i.e., present-day climate simulations) and to remove the structural biases using the statistical bias correction method (i.e. PQM method; see Sect. 2.4). It is assumed that model bias does not change with time.

Here, we evaluate the reliability of the MRCM ensemble simulations. Figure 4 illustrates the spatial distribution of mean dry-bulb (TA) and wet-bulb (TW) temperatures during June-September (JJAS) derived from observation and model biases. The MRCM ensemble reasonably captures the spatial patterns of dry- and wet-bulb temperatures during monsoon season, although it overall underestimates the temperatures showing a noticeable cold bias with amounts greater than $0.6{ }^{\circ} \mathrm{C}$ in the southwestern low-lying region (Fig. 4b, e). In addition, MRCM simulations driven by the three different models consistently overestimate the temperatures along the southeastern border of the country. We also show that structural model biases are effectively decreased through the bias-correction step with the PQM method. As expected, the bias-corrected MRCM ensemble shows better agreement with observed climatological patterns in terms of spatial distribution and magnitude.

The spatial distributions of mean rainfall during the whole year and monsoon season are shown in Fig. 5. As discussed in the previous section, the observed rainfall is characterized by a pronounced gradient between low rainfall in the low-elevation plain and high rainfall in mountainous areas (Fig. 5a, d). The ensemble mean of the MRCM simulations tends to underestimate rainfall in the low-lying coastal region. Moreover, it noticeably overestimates rainfall over northeastern regions. The spatial pattern of rainfall bias from the reference simulation is similar to that from the perfect boundary forcing simulation driven by ERA-Interim (Fig. 3), which can thus be interpreted as the MRCM's systematic bias. These systematic biases are in line with the results of previous studies and can be effectively eliminated through the PQM method (Kang et al. 2019a, 2019b). The bias-corrected rainfall derived from the MRCM ensemble agrees well with observation, with bias less than $1 \mathrm{~mm} /$ day. The above results, in terms of systematic temperature and rainfall biases, provide an overview of the MRCM performance on 

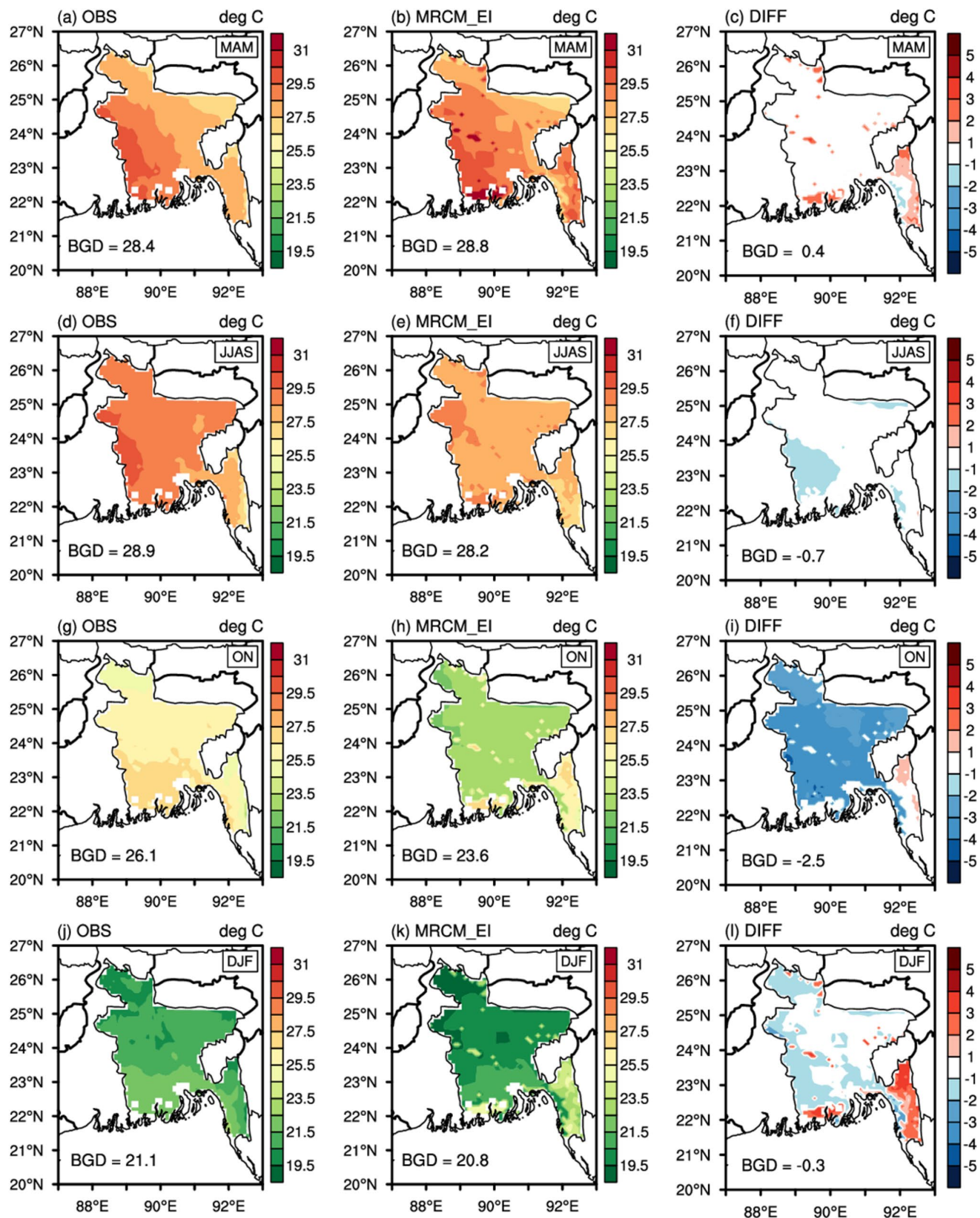

Fig. 2 Spatial distribution of seasonal temperature for the pre-monsoon (MAM; a-c), monsoon (JJAS; d-f), post-monsoon ( $\mathrm{ON} ; \mathbf{g}-\mathbf{i})$, and winter seasons (DJF; $\mathbf{j}-\mathbf{l}$ ) derived from TerraClimate (OBS; a, d, $\mathbf{g}, \mathbf{j}$ ), MRCM simulations driven by ERA-interim (MRCM_EI; b, $\mathbf{e}, \mathbf{h}, \mathbf{k}$ ), and difference between MRCM_EI and OBS (DIFF; $\mathbf{c}, \mathbf{f}, \mathbf{i}$, l). The OBS data are interpolated to the coarser MRCM grid. Areaaveraged value over Bangladesh (BGD; only land area) are given on the bottom left corner of each plot (unit: ${ }^{\circ} \mathrm{C}$ ) 

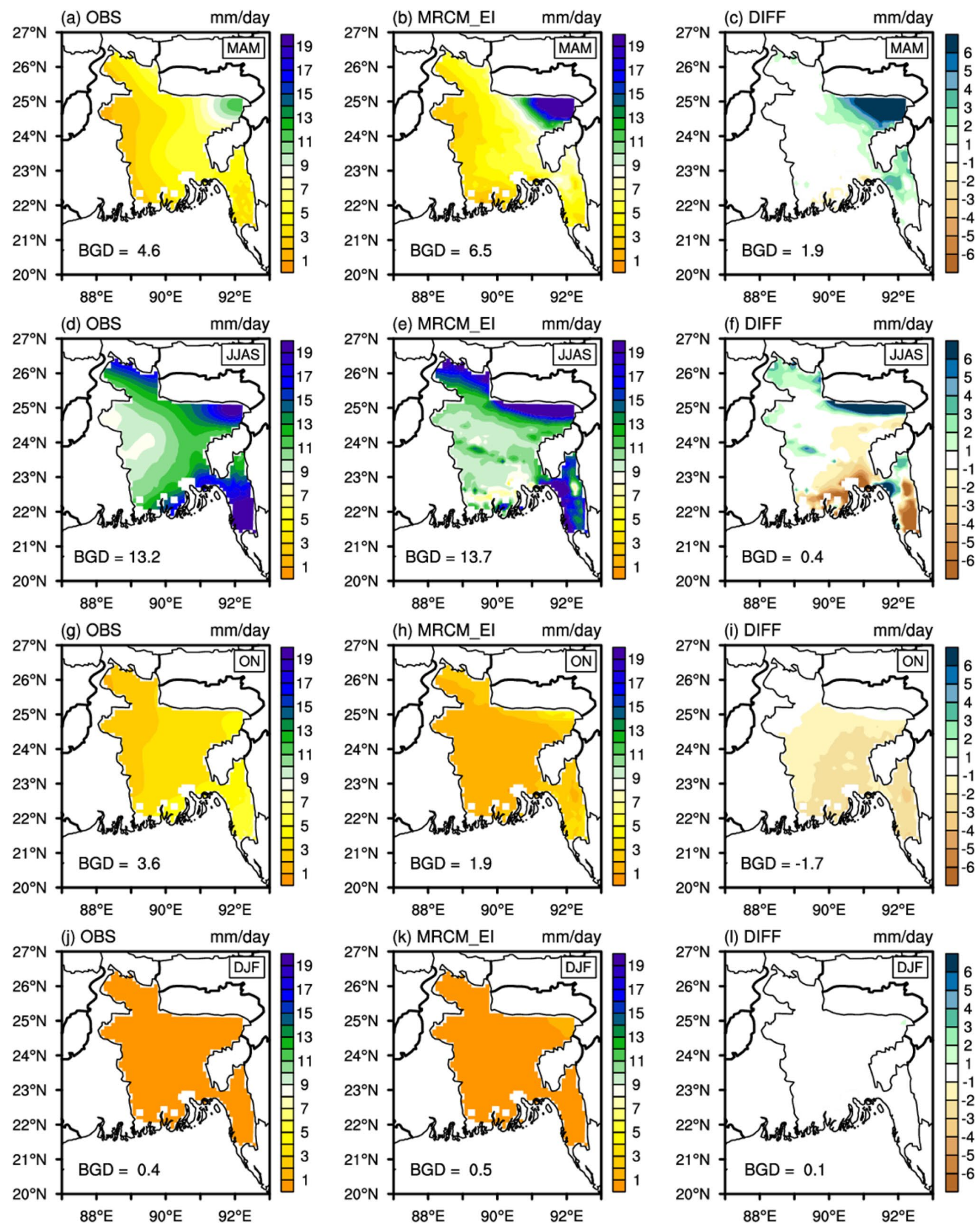

Fig. 3 Same as Fig. 2, but for rainfall (unit: mm/day) 
(a) OBS

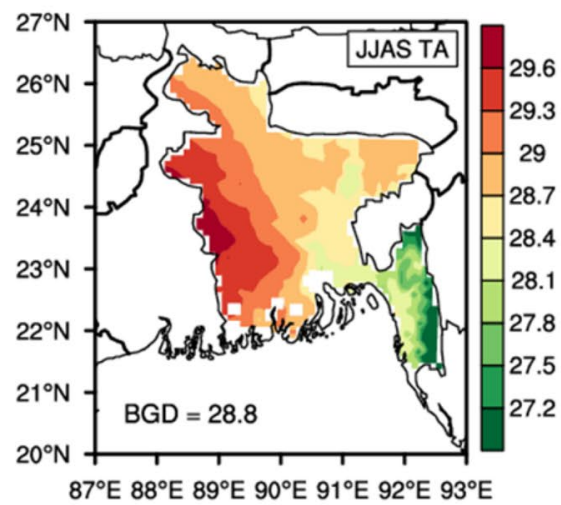

(d) OBS

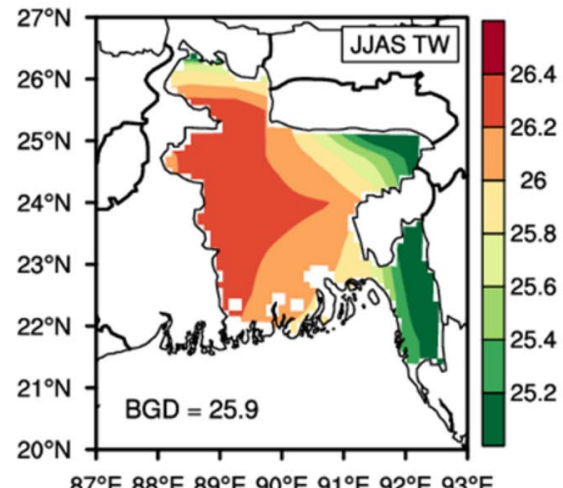

(b) MRCM - OBS

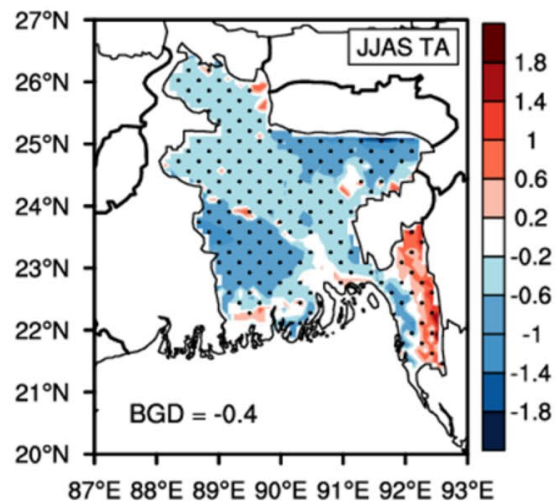

(e) MRCM - OBS

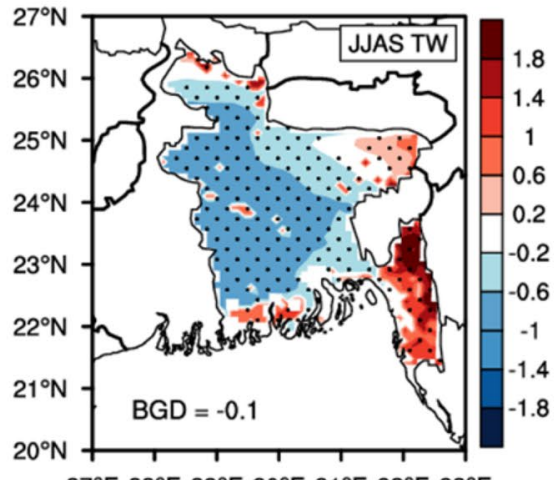

(c) MRCM_BC - OBS

$\operatorname{deg} \mathrm{C}$ $87^{\circ} \mathrm{E} 88^{\circ} \mathrm{E} 89^{\circ} \mathrm{E} 90^{\circ} \mathrm{E} 91^{\circ} \mathrm{E} 92^{\circ} \mathrm{E} 93^{\circ} \mathrm{E}$

(f) MRCM_BC - OBS $\operatorname{deg} \mathrm{C}$

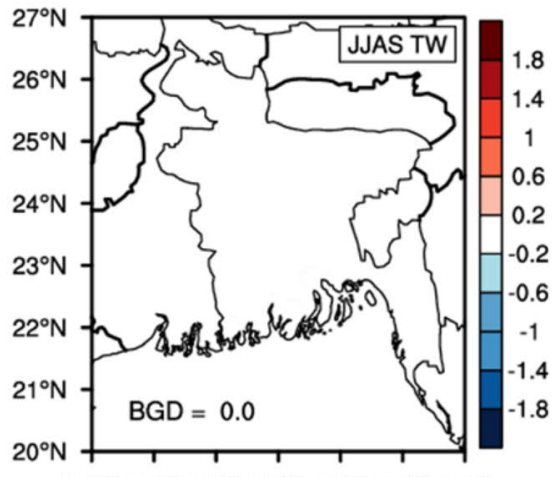

Fig. 4 Spatial distribution of climatological daily mean dry- and wetbulb temperatures (TA and TW; unit: ${ }^{\circ} \mathrm{C}$ ) during the monsoon season (June to September; JJAS) for reference period (1976-2005). a TA derived from TerraClimate (1976-2005), b-c difference of TA between MRCM ensemble $\mathbf{b}$ without- or $\mathbf{c}$ with bias correction and TerraClimate, d TW derived from ERA-Interim (1979-2008), e-f difference of TW between MRCM ensemble e without- or $\mathbf{f}$ with bias correction and ERA-Interim. Stippling indicates regions where the differences are statistically significant at the 5\% level as determined by a two-sided Student's t-test. Area-averaged value over land are given on the bottom left corner of each plot (unit: ${ }^{\circ} \mathrm{C}$ ) regional to local scales before projecting the future climate change (Figs. 4 and 5).

\subsection{Projected changes in near-term temperature}

Based on the MRCM ensemble projection, heat stress over Bangladesh is expected to worsen in the near future as climate change progresses. Figure 6 shows the changes in dryand wet-bulb temperatures under the business-as-usual scenario. The ensemble mean of the MRCM simulations shows a generalized warming of mean temperature with magnitude above $1.0{ }^{\circ} \mathrm{C}$ across the country during monsoon season. The largest increase is expected in the western part of the country including Dhaka, Bogra, Ishurdi, and Jessore (Fig. 6c). Along with rising temperature, significant increases in wetbulb temperature (increase by average of about $1.1{ }^{\circ} \mathrm{C}$ ) are also identified in the overall region, although the spatial pattern of change in wet-bulb temperature differs from that for the dry-bulb temperature. That is, the increase in wet-bulb temperature is spatially homogeneous, with no major difference depending on the region, except for some coastal and mountainous regions (e.g., Cox's Bazar; Fig. 6f). To quantitatively examine the projected risk of heat stress, we applied the U.S. National Weather Service (USNWS) heat index risk categories, including the danger and extreme danger thresholds which approximately correspond to a wet-bulb temperature of $27{ }^{\circ} \mathrm{C}$ and $31.2{ }^{\circ} \mathrm{C}$, respectively, under the specific climatic condition of Bangladesh (Suppl. Figure 2; Kang and Eltahir, 2018; Kang et al., 2019b). This approach, defining the thresholds of heat stress using the impacts of temperature and humidity, is in line with Nissan et al. (2017). They found significant effects of day- and nighttime temperatures and humidity in shaping heat-related deaths and proposed a heat-wave definition for Bangladesh that could inform the development of a heat early warning system. The mean wetbulb temperature is expected to exceed the USNWS danger threshold of $27^{\circ} \mathrm{C}$, primarily in the interior region, which 
(a) OBS

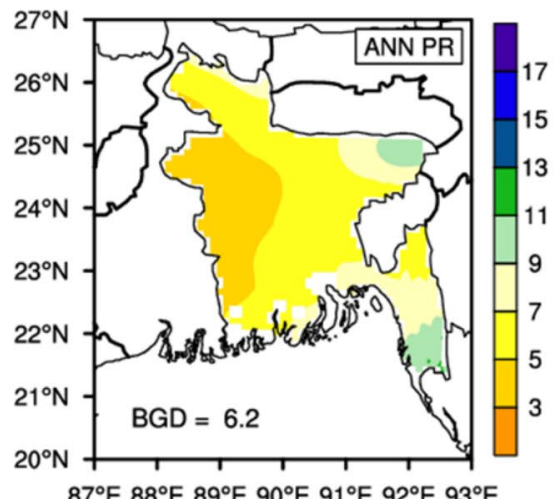

(d) OBS

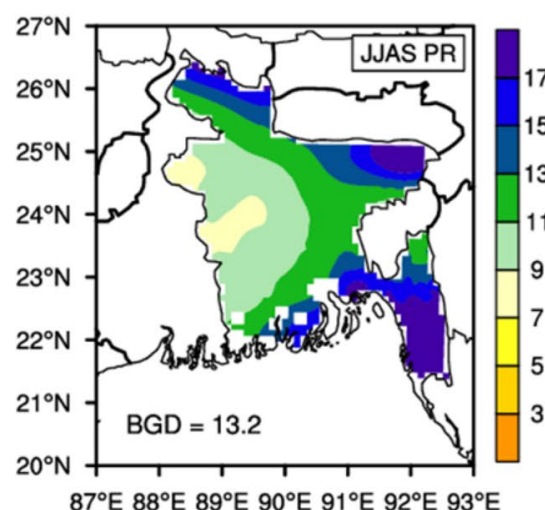

(b) MRCM - OBS

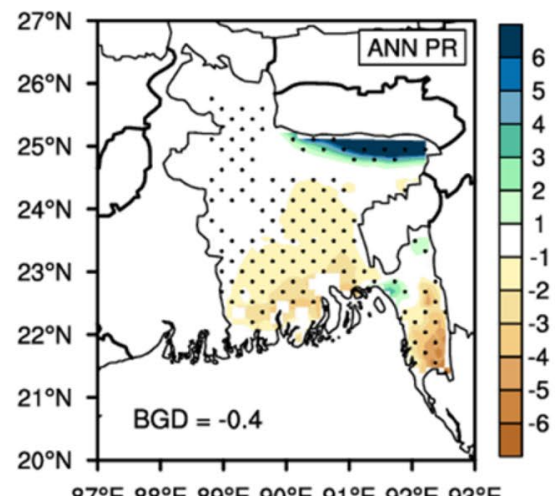

(e) MRCM - OBS

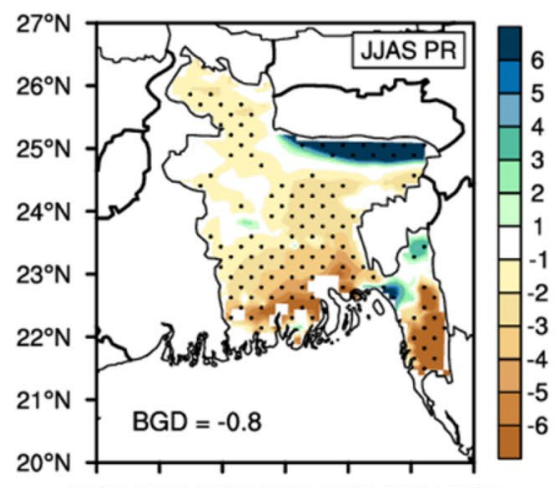

$87^{\circ} \mathrm{E} 88^{\circ} \mathrm{E} 89^{\circ} \mathrm{E} 90^{\circ} \mathrm{E} 91^{\circ} \mathrm{E} 92^{\circ} \mathrm{E} 93^{\circ} \mathrm{E}$ (c) MRCM BC - OBS $\mathrm{mm} / \mathrm{day}$

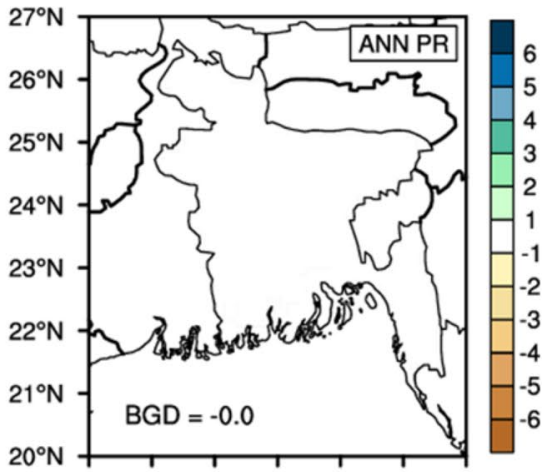

$87^{\circ} \mathrm{E} 88^{\circ} \mathrm{E} 89^{\circ} \mathrm{E} 90^{\circ} \mathrm{E} 91^{\circ} \mathrm{E} 92^{\circ} \mathrm{E} 93^{\circ} \mathrm{E}$

(f) MRCM_BC - OBS mm/day

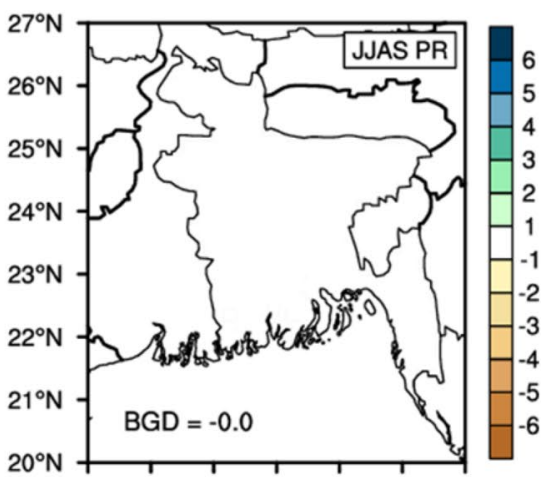

$87^{\circ} \mathrm{E} 88^{\circ} \mathrm{E} 89^{\circ} \mathrm{E} 90^{\circ} \mathrm{E} 91^{\circ} \mathrm{E} 92^{\circ} \mathrm{E} 93^{\circ} \mathrm{E}$
Fig. 5 Spatial distribution of climatological daily mean precipitation (PR; unit: $\mathrm{mm} /$ day) annually and during the monsoon season (June to September; JJAS) for reference period (1976-2005). a Annual mean PR derived from TerraClimate (1976-2005), b-c difference of annual mean PR between MRCM ensemble $\mathbf{b}$ without- or $\mathbf{c}$ with bias correction and TerraClimate, d JJAS mean PR derived from TerraClimate,

implies that dangerous heat stress will become normal in most low-lying plains over Bangladesh in next few decades.

Consistent with the increases in mean dry- and wet-bulb temperatures, we also project the amplification of heat stress seasonally for the near-term future. Figure 7 shows the projected changes in annual cycle of maximum wet-bulb temperature for seven major cities. In a present-day climate, the daily maximum wet-bulb temperature is approaching or has already exceeded the USNWS danger threshold $\left(27^{\circ} \mathrm{C}\right)$ over most stations during monsoon season. As the century progresses, more warming is projected for the monsoon season as compared to the other seasons. Especially, increases in mean maximum wet-bulb temperature during monsoon season are expected to be well above the danger threshold across all target stations under the business-as-usual scenario. Of particular note, the period of suffering from the heat stress is expected to be longer than those we observed in the current climate. Western Bangladesh cities, including Jessore, Bogra, and Ishurdi, where heat-related risk is e-f difference of PR between MRCM ensemble e without- or $\mathbf{f}$ with bias correction and TerraClimate. Stippling indicates regions where the differences are statistically significant at the $5 \%$ level as determined by a two-sided Student's t-test. Area-averaged value over land are given on the bottom left corner of each plot (unit: $\mathrm{mm} /$ day)

already high, will experience more extreme heat waves in the near-term future.

To qualitatively assess the change in extreme heat waves events, we also analyze the probability distribution function of daily maximum wet-bulb temperature (Fig. 8). For the historical period, the daily maximum wet-bulb temperature is almost never observed more than the $31.2{ }^{\circ} \mathrm{C}$ extreme danger threshold except for Jessore. However, under the business-as-usual scenario, the extremes of daily maximum wet-bulb temperature are projected to exceed the extreme danger threshold $\left(31.2{ }^{\circ} \mathrm{C}\right)$ for many urban population centers, including Dhaka, Jessore, Bogra, Sylhet, Ishurdi, Chittagong, and Cox's Bazar, by the middle of the century. Particularly, western Bangladesh cities, including Jessore, Bogra and Ishurdi, are projected to experience extreme heat stress episodes with a maximum wet-bulb temperature exceeding $32{ }^{\circ} \mathrm{C}$ and approaching $33{ }^{\circ} \mathrm{C}$, which is considered extremely dangerous for most humans. While the general shape of the distribution of maximum wet-bulb temperature 
(a) REF TA

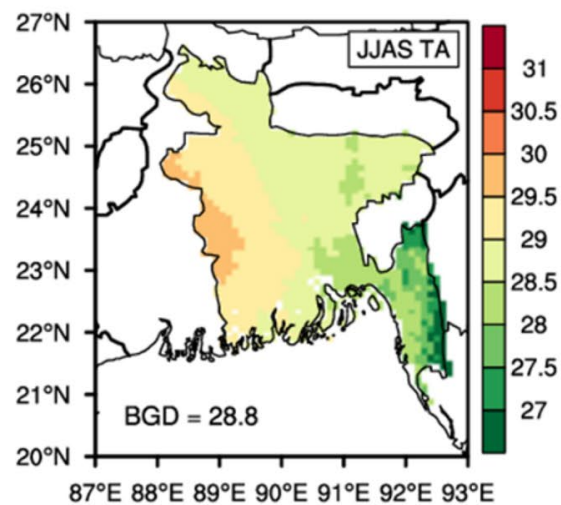

(d) REF TW

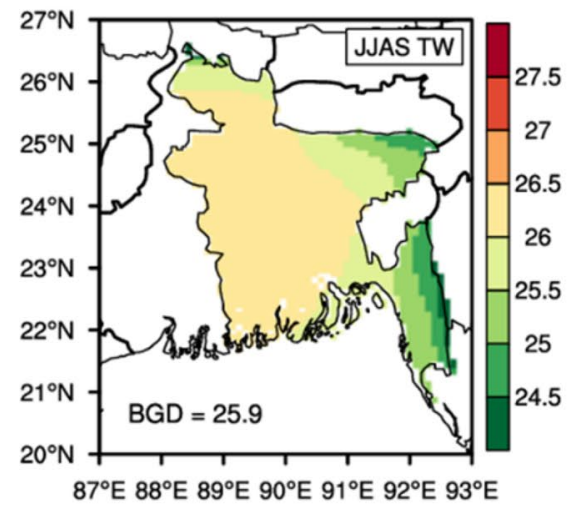

(b) R85 TA

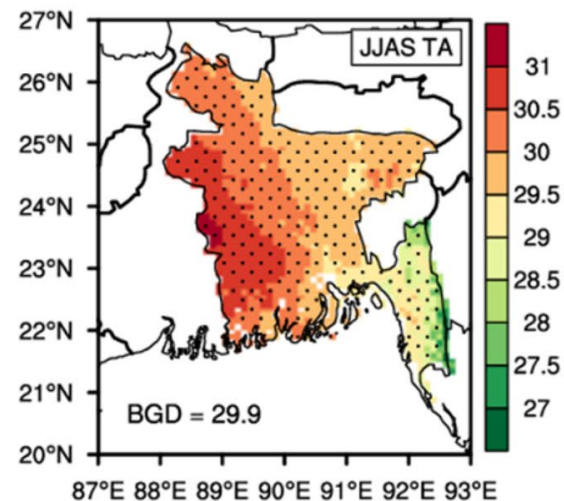

(e) R85 TW

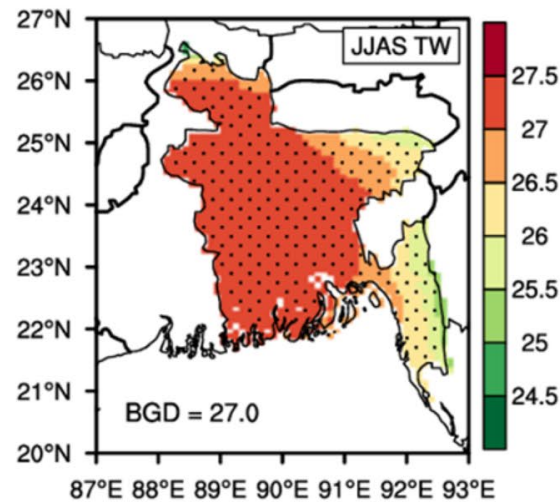

(c) DIFF TA

$\operatorname{deg} C$

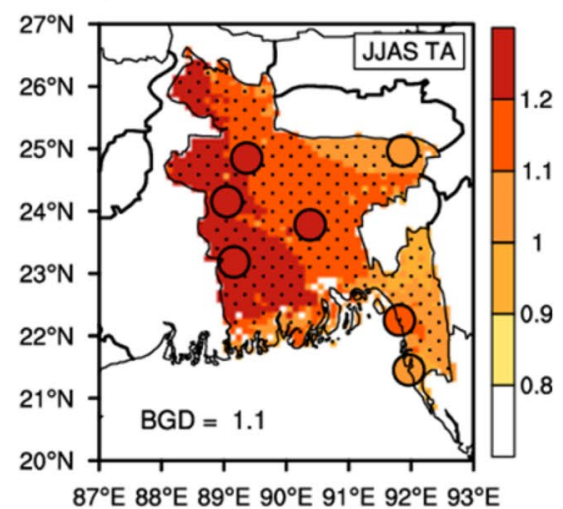

(f) DIFF TW

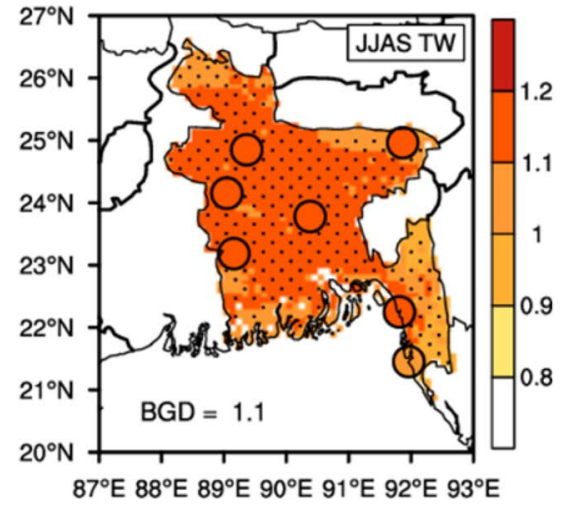

Fig. 6 Spatial distribution of climatological daily mean $\mathbf{a}-\mathbf{b}$ dry- and d-e wet-bulb temperatures (TA and TW; unit: ${ }^{\circ} \mathrm{C}$ ) during the monsoon season (June to September; JJAS). TA derived from MRCM ensemble for a reference period, $\mathbf{b}$ near future period under RCP8.5 scenario, and $\mathbf{c}$ its change. TW derived from MRCM ensemble for $\mathbf{d}$ reference period, e near future period under RCP8.5 scenario, and $\mathbf{f}$ its change. Coloured dots $\mathbf{c}, \mathbf{f}$ indicate the future changes at 7 meteorological stations (Dhaka, Jessore, Bogra, Sylhet, Ishurdi, Chittagong, and Cox's Bazar). Stippling indicates agreement by three MRCM simulations on the sign of the change. Area-averaged value over land are given on the bottom left corner of each plot (unit: ${ }^{\circ} \mathrm{C}$ )

climate change would lead to a stronger projected decrease in return period in the western regions, in particular, Bogra, Ishurdi, and Jessore. These cities can be considered hotspots because they are likely to experience more frequent extremes of wet-bulb temperature (Fig. 8), with the greatest reduction in return period of extreme heat at less than 10 years.

\subsection{Projected changes in near-term rainfall}

Figure 10 shows the projected change in mean rainfall during annual and monsoon seasons. Based on bias-corrected MRCM ensemble projections, annual mean precipitation generally increases by about $4 \%$ in Bangladesh in a warmer climate. Particularly, a small but significant increase in annual mean rainfall is projected mostly in Northern region (e.g., Bogra and Sylhet) of Bangladesh with a magnitude of more than $6 \%$ as compared to the reference period (Fig. 10c). In addition, our ensemble projection shows a significant increase of monsoon rainfall, by about $6 \%$, over the target 
Fig. 7 The 30-year mean seasonal cycle of TWmax for the seven cities (a Dhaka, b Jessore, c Bogra, d Sylhet, e Ishurdi, f Chittagong, g Cox's Bazar) over Bangladesh derived from station observation (1984-2013; black), and ensemble mean of MRCM simulations under historical (1976-2005; blue) and RCP8.5 scenarios (2021-2050; red). Horizontal dashed yellow and red lines indicate the danger $(27$ $\left.{ }^{\circ} \mathrm{C}\right)$ and extreme danger $(31.2$ $\left.{ }^{\circ} \mathrm{C}\right)$ thresholds defined by the U.S. National Weather Service, respectively (a) Dhaka

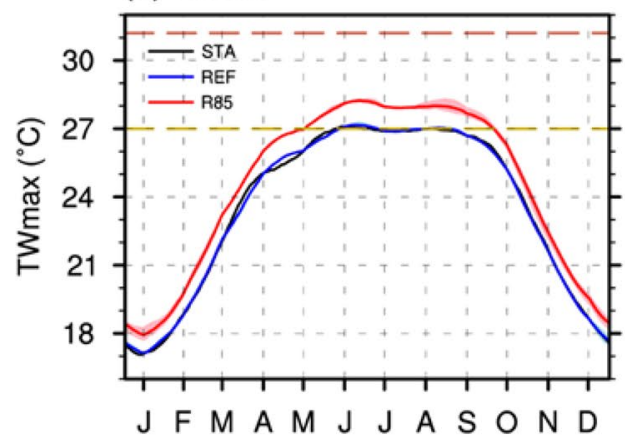

(c) Bogra

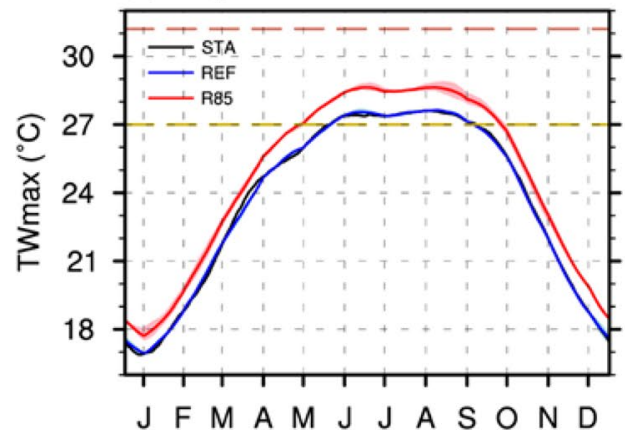

(e) Ishurdi

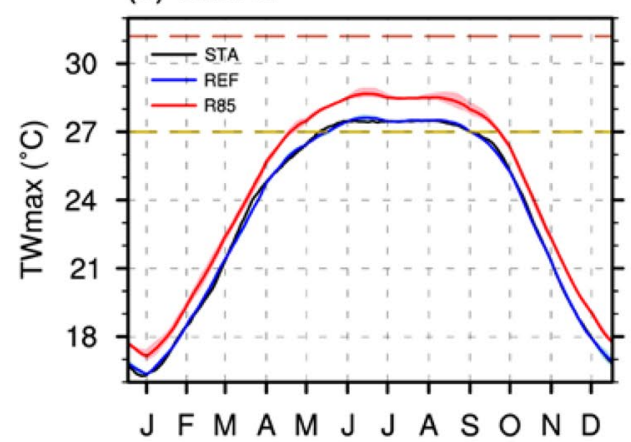

(g) Cox's Bazar

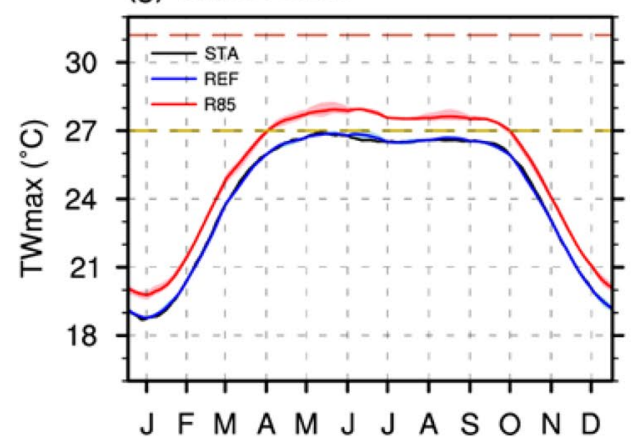

(b) Jessore

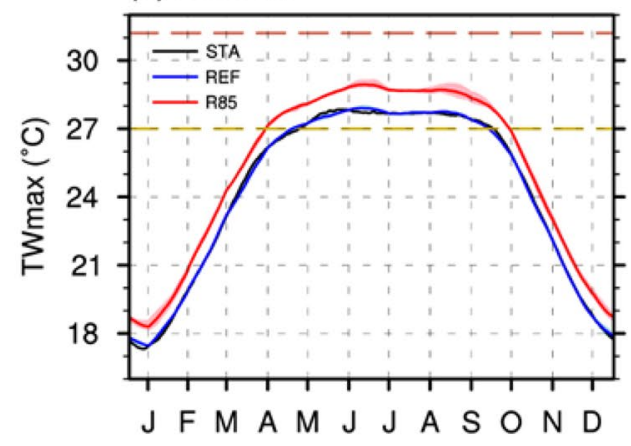

(d) Sylhet

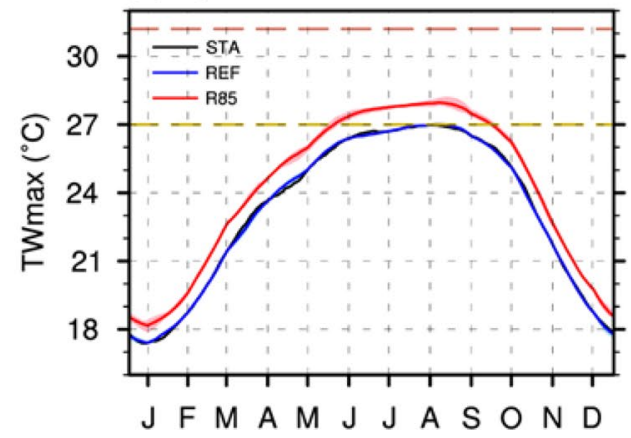

(f) Chittagong

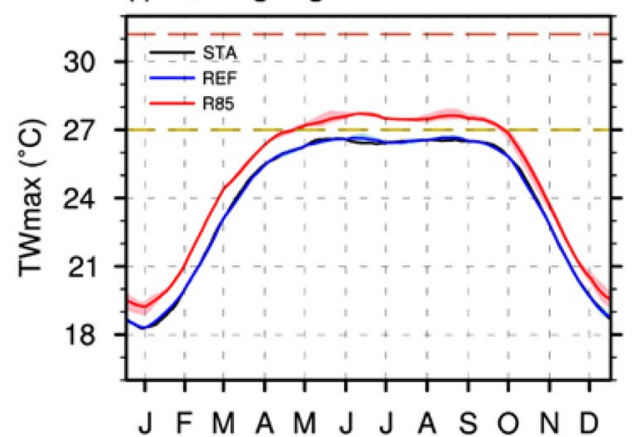


Fig. 8 Histogram of daily maximum wet-bulb temperature $\left(\mathrm{TWmax} ;{ }^{\circ} \mathrm{C}\right)$ for the seven cities (a Dhaka, b Jessore, c Bogra, d Sylhet, e Ishurdi, f Chittagong, g Cox's Bazar) over Bangladesh. Black, blue, and red lines represent the station observation, historical (1976-2005), and RCP8.5 (2021-2050) scenarios, respectively. Values indicated within each plot represent the 50th and 95 th percentile thresholds. Vertical dashed yellow and red lines indicate the danger (27

$\left.{ }^{\circ} \mathrm{C}\right)$ and extreme danger (31.2

$\left.{ }^{\circ} \mathrm{C}\right)$ thresholds defined by the

U.S. National Weather Service, respectively (a) Dhaka

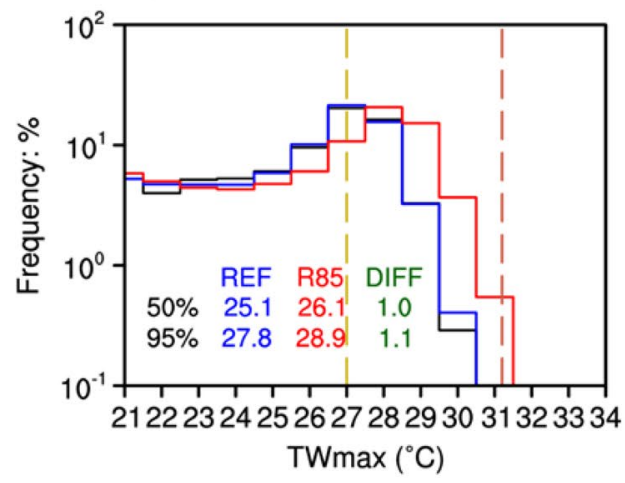

(c) Bogra

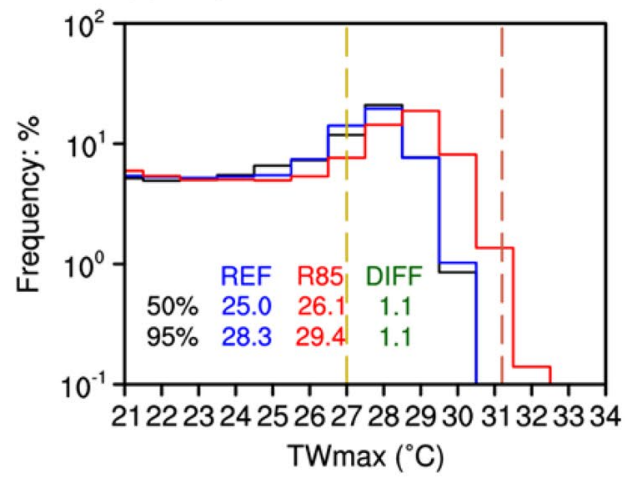

(e) Ishurdi

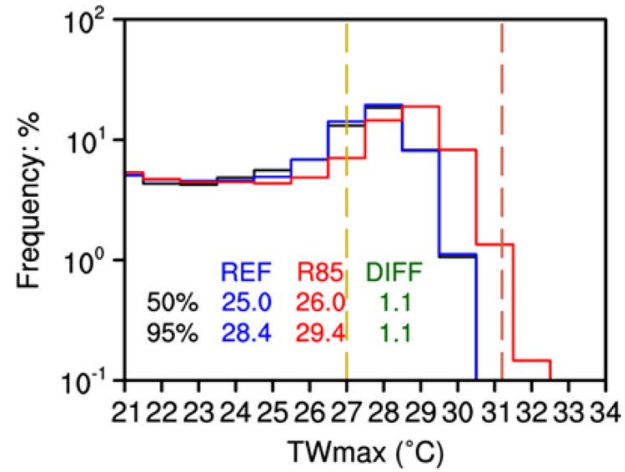

(g) Cox's Bazar

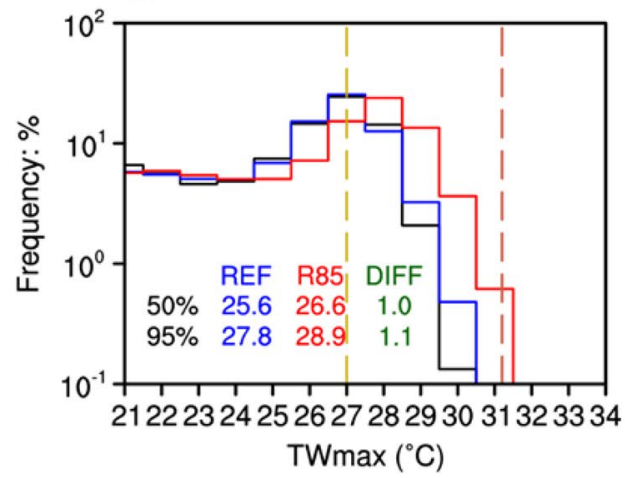

(b) Jessore

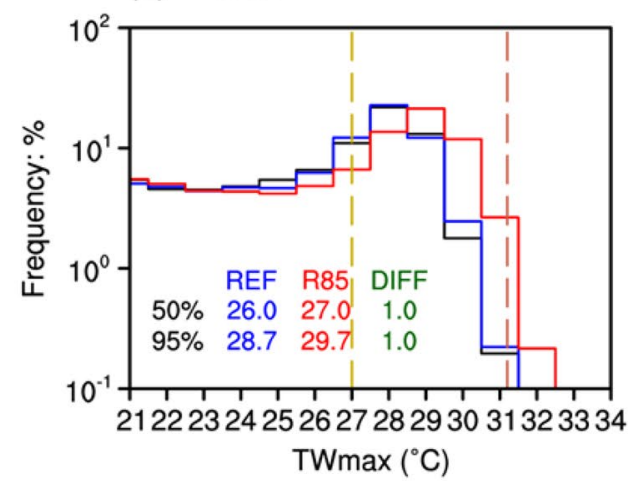

(d) Sylhet

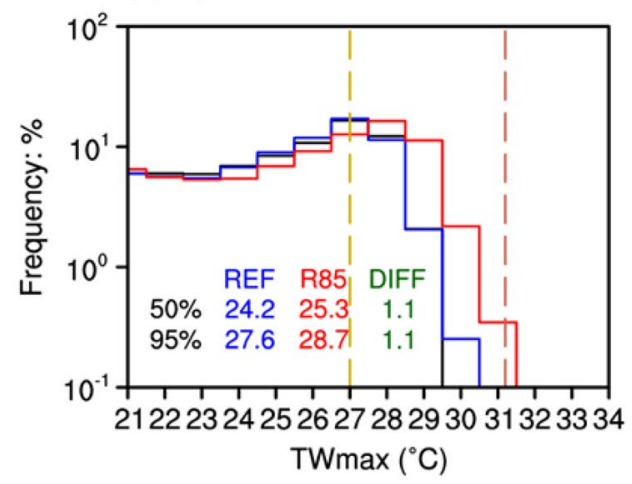

(f) Chittagong

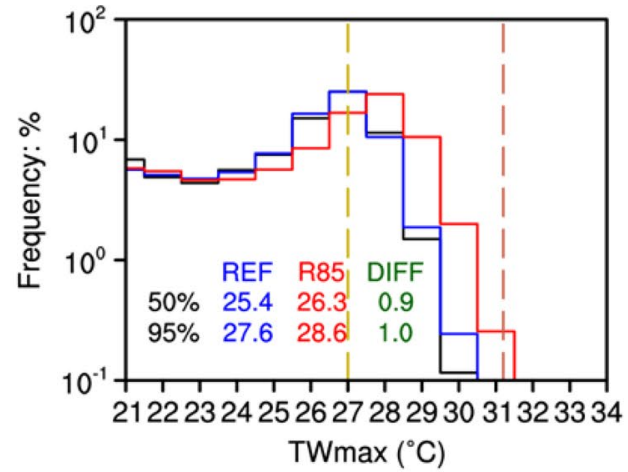


Fig. 9 Return periods of biascorrected annual maximum wetbulb temperature $\left(\mathrm{TWmax} ;{ }^{\circ} \mathrm{C}\right)$ for the seven cities (a Dhaka, b Jessore, c Bogra, d Sylhet, e Ishurdi, f Chittagong, g Cox's Bazar) over Bangladesh. Blue, and red dots represent the historical (1976-2005), and RCP8.5 (2021-2050) scenarios, respectively. Vertical dashed red line indicates the extreme danger $\left(31.2^{\circ} \mathrm{C}\right)$ threshold defined by the U.S. National Weather Service (a)

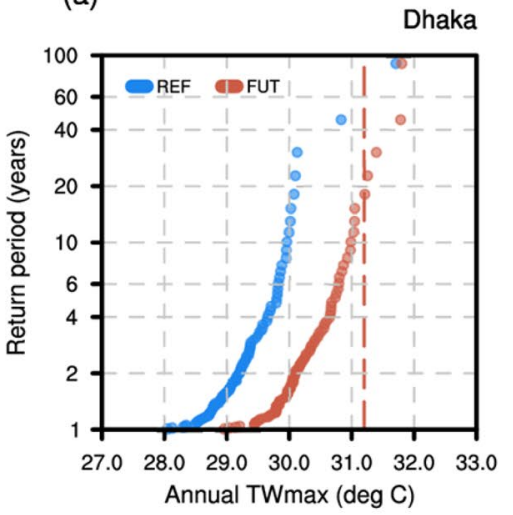

(c)

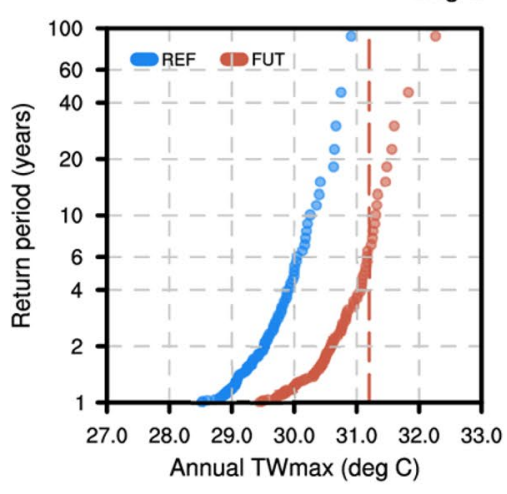

(e)

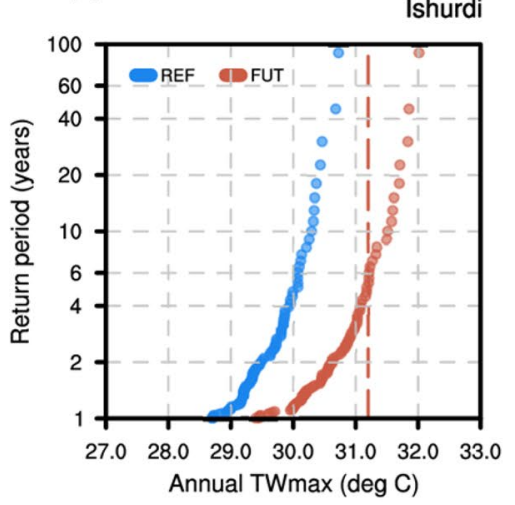

(g)

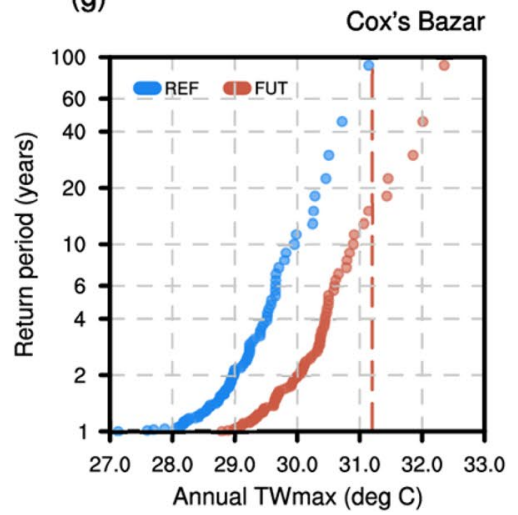

(b)

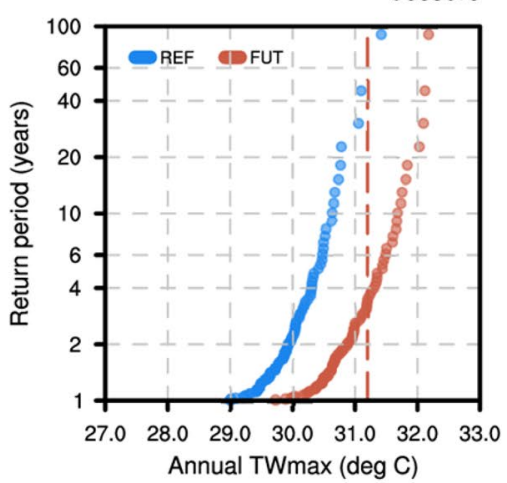

(d)

Sylhet

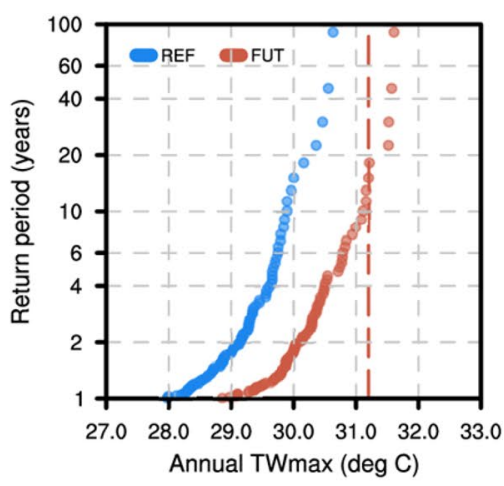

(f)

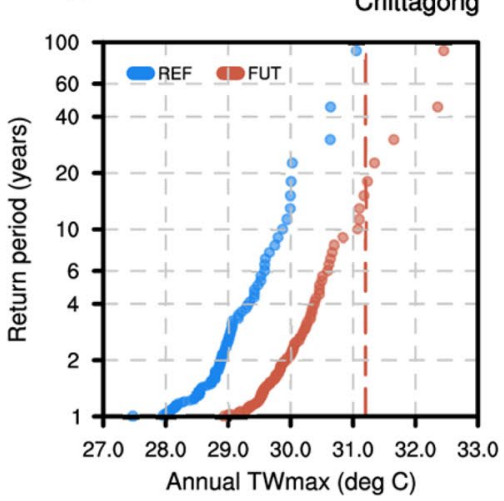


(a) REF

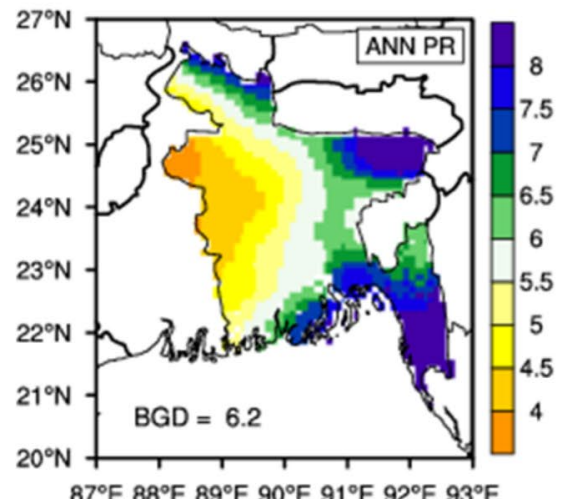

(d) REF

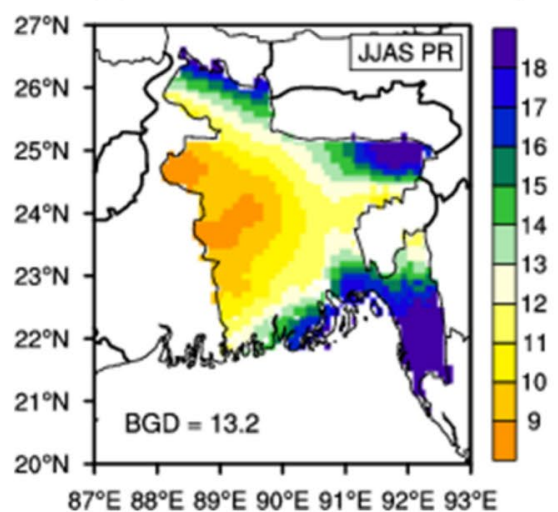

(b) R85

$\mathrm{mm} / \mathrm{day}$

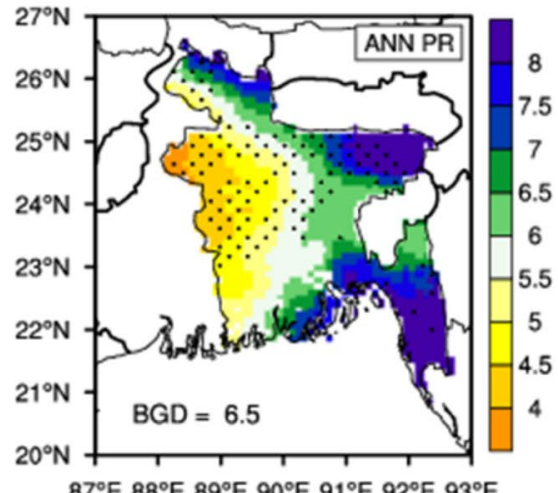

(e) R85

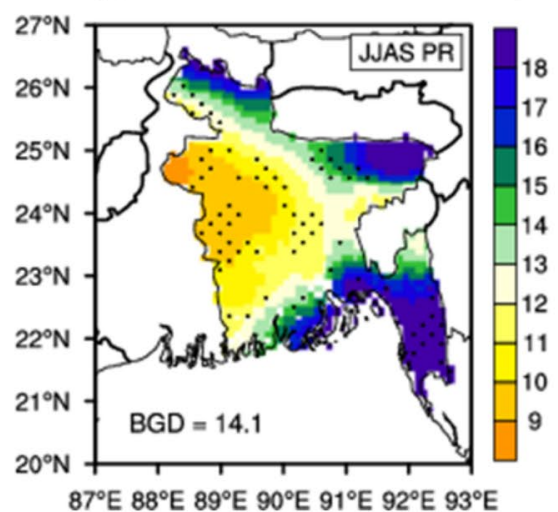

(c) DIFF

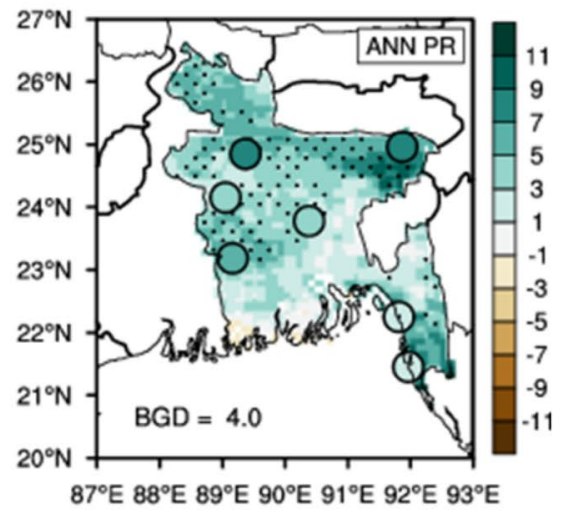

(f) DIFF

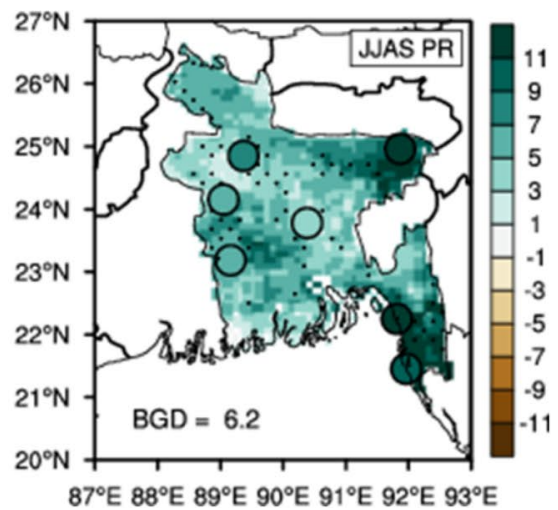

Fig. 10 Spatial distribution of climatological daily mean rainfall (PR; unit: $\mathrm{mm} /$ day) annually and during the monsoon season (June to September; JJAS). Annual mean PR derived from MRCM ensemble for a reference period, $\mathbf{b}$ near future period under RCP8.5 scenario, and $\mathbf{c}$ its change. JJAS PR derived from MRCM ensemble for $\mathbf{d}$ reference period, e near future period under RCP8.5 scenario, and $\mathbf{f}$ its change.
Coloured dots $\mathbf{c}, \mathbf{f}$ indicate the future changes at 7 meteorological stations (Dhaka, Jessore, Bogra, Sylhet, Ishurdi, Chittagong, and Cox's Bazar). Stippling indicates agreement by three MRCM simulations on the sign of the change. Area-averaged value over land are given on the bottom left corner of each plot (unit: $\mathrm{mm} /$ day)

there is relatively weaker seasonality in the western cities including Dhaka, Jessore, Bogra, and Ishurdi. In the future projection, increases in rainfall during the monsoon season appear in most target cities, though small. Eastern cities, such as Sylhet and Chittagong will likely experience increased rainfall of around 14\%, during monsoon season in the coming few decades. The consistency among all simulations driven by the three different GCMs gives high confidence in the results. The change in the incidence of extreme rainfall events is further examined through return period analysis (Fig. 12). Based on the MRCM projections with bias correction, the return period of annual maximum precipitation does not change significantly in response to the RCP8.5 GHG forcing despite the increase in mean precipitation over the region. Most cities show slight decreases in return periods, which are, however, not significant except for Cox's Bazar. These weak changes reinforce the insignificant impact of near-term climate change on the rainfall extremes. 
Fig. 11 The 30-year mean seasonal cycle of rainfall for the seven cities (a Dhaka, b Jessore, c Bogra, d Sylhet, e Ishurdi, f Chittagong, g Cox's Bazar) over Bangladesh derived from station observation (1979-2008; black), and ensemble mean of MRCM simulations under historical (1976-2005; blue) and RCP8.5 scenarios (2021-2050; red) (a) Dhaka

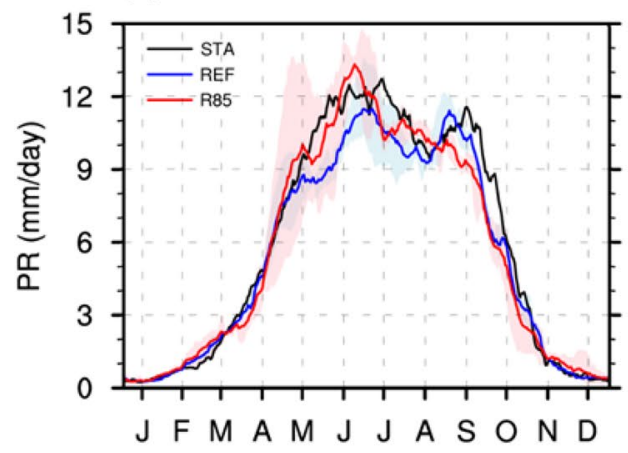

(c) Bogra

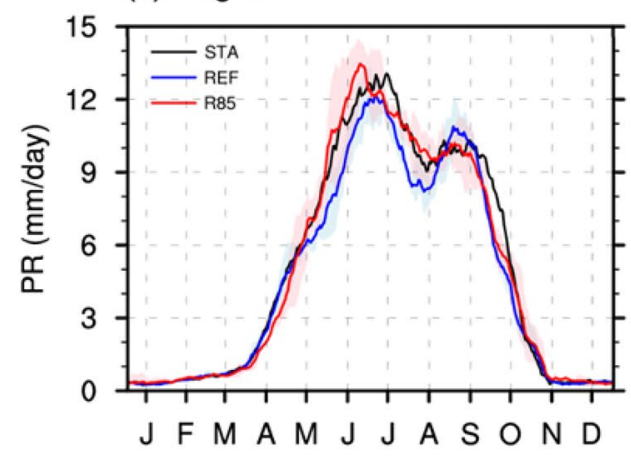

(e) Ishurdi

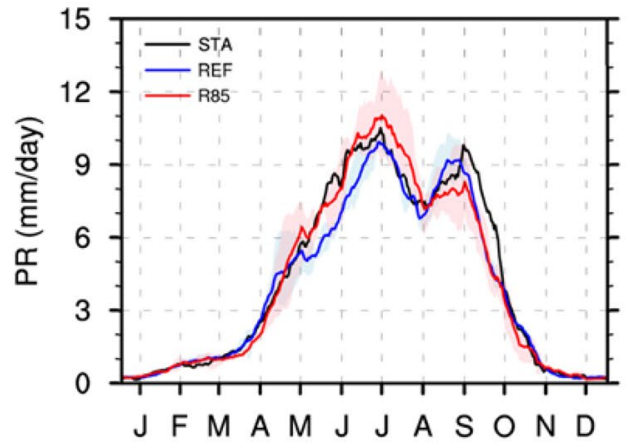

(g) Cox's Bazar

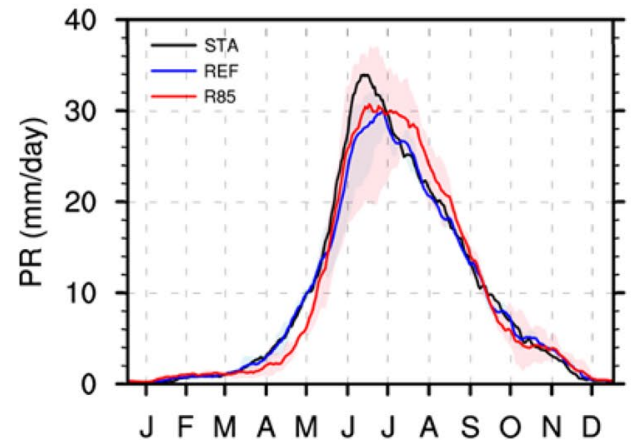

(b) Jessore

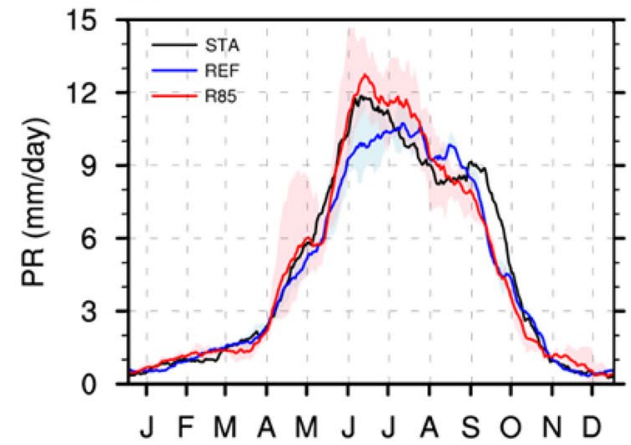

(d) Sylhet

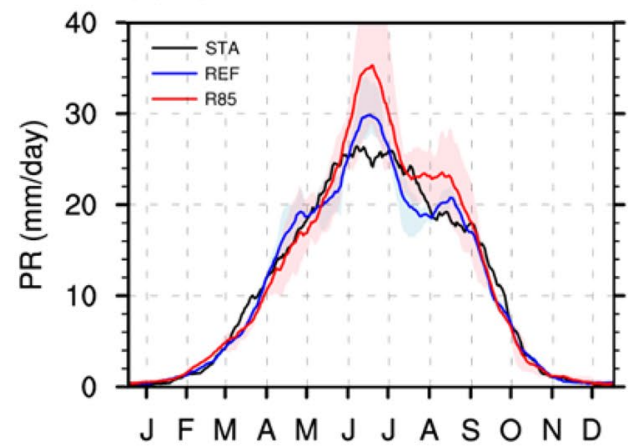

(f) Chittagong

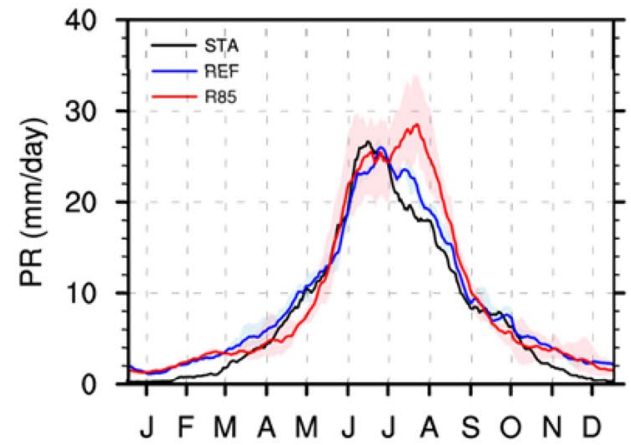


Fig. 12 Return periods of bias-corrected annual maximum precipitation (PR; mm/day) for the seven cities (a Dhaka, b Jessore, c Bogra, d Sylhet, e Ishurdi, f Chittagong, g Cox's Bazar) over Bangladesh. Blue, and red dots represent the historical (1976-2005), and RCP8.5 (2021-2050) scenarios, respectively (a)

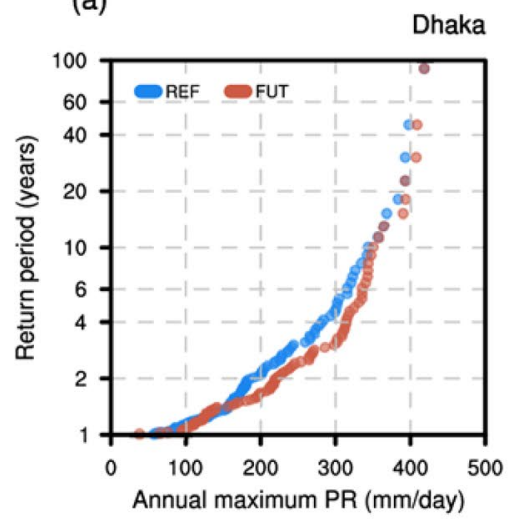

(c)

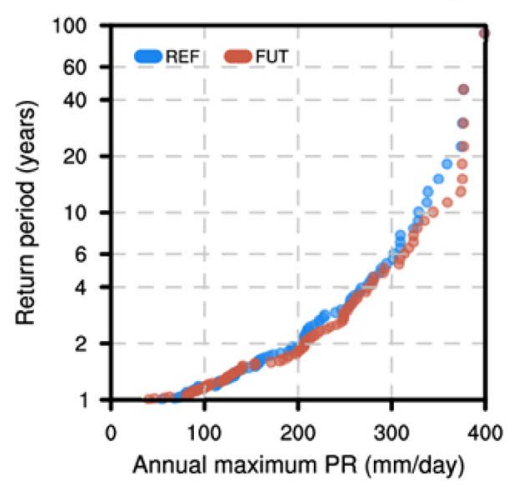

(e)

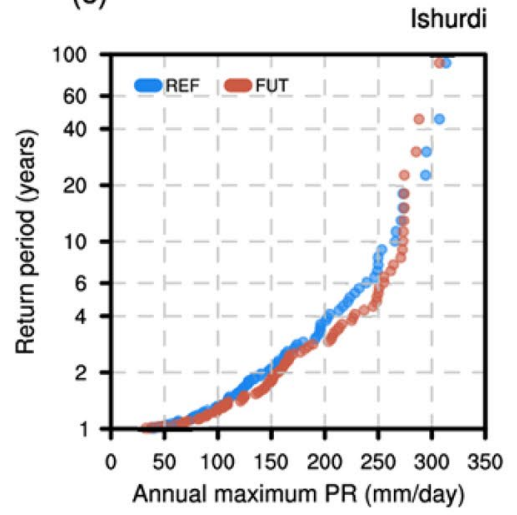

(g)

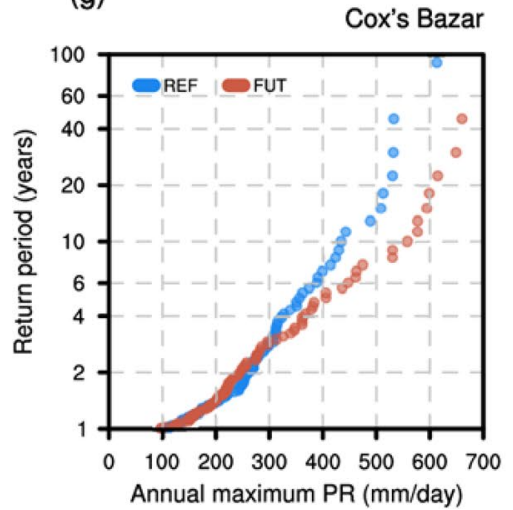

(b)

Jessore

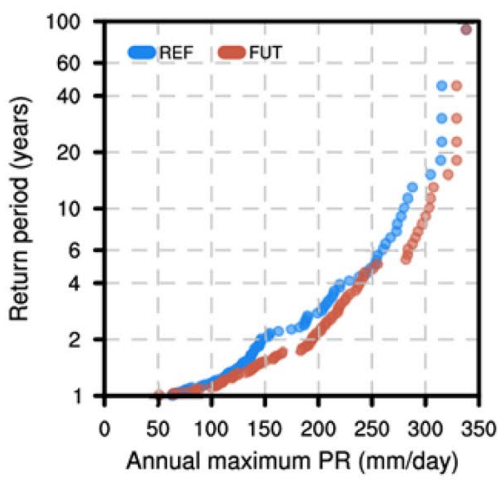

(d)

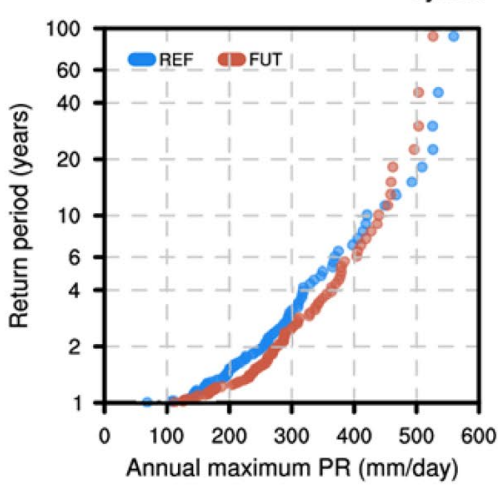

(f)

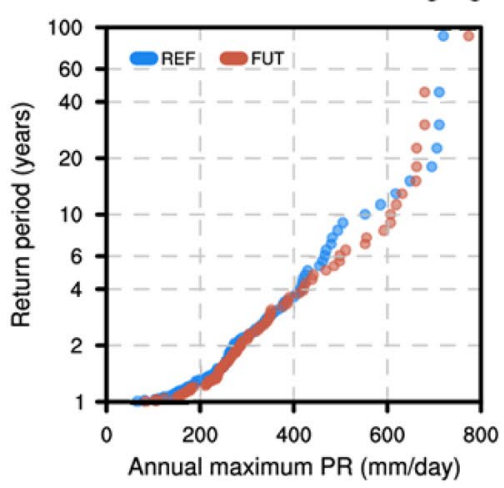




\section{Summary and conclusions}

Many parts of the world experience climate extremes, such as heat waves and heavy rainfalls. Among the countries, Bangladesh is considered one of most vulnerable countries to the adverse impacts of climate change. It is generally agreed that the projected increase in temperature and humidity will exacerbate the risk of extreme climate events in the country over the next few decades (e.g., Im et al. 2017a). However, there is lack of understanding of the direction, magnitude and spatial pattern of projected climatic changes at regional to local scales.

In this study, we used an ensemble of high-resolution regional climate model simulations driven by three CMIP5 GCMs to project near-term changes in temperature and rainfall extremes across Bangladesh under the business-asusual scenario. We showed that the MRCM ensemble with statistical bias correction is capable of capturing regionspecific climate information over the target domain.

Under the business-as-usual scenario we show that heatwaves will become more frequent and severe in Bangladesh. It is also projected that the western part of Bangladesh, including Bogra, Ishurdi, and Jessore, is particularly susceptible to extreme heat stress with the maximum wetbulb temperature exceeding the extreme danger threshold $\left(31.2{ }^{\circ} \mathrm{C}\right.$ defined by USNWS), which was rarely observed over this area in the current climate. Furthermore, the enhanced GHG forcing under the RCP8.5 scenario will increase the likelihood of the reoccurrence of extreme danger level heat extremes. However, changes in rainfall, unlike temperature changes, are small across the region, with a slight increasing tendency. Area-averaged annual mean and monsoon season rainfall in Bangladesh are expected to slightly increase by about $4 \%$ and $6 \%$, respectively, with the maximum centered in eastern mountainous regions during the summer months. Furthermore, the return period of annual maximum precipitation will experience small changes in Cox's Bazar, however the same variable is likely to remain close to its present climate value in most regions.

Our study further illustrates that Bangladesh faces climate change associated risks beyond the risks in coastal areas. It is generally agreed that coastal regions of Bangladesh are particularly susceptible to the impacts of sea level rise, the extreme cyclones (Ali 1999; OECD 2003; Dasgupta et al. 2014). However, using an ensemble of projections, we also show that inland locations are likely to be threatened by deadly heat waves, especially in localized hotspots in western parts of Bangladesh. Therefore, populations moving inland due to coastal climate related disasters will still be faced with extreme heatwaves away from the coast. This study provides a crucial glimpse of the near future climate, with projections based on high-resolution MRCM simulation that provide significant information to help inform the development of sound adaptation strategy.

Supplementary Information The online version contains supplementary material available at https://doi.org/10.1007/s00382-021-05856-z.

Acknowledgements This material is based upon work supported by the Under Secretary of Defense for Research and Engineering under Air Force Contract No. FA8702-15-D-0001. Any opinions, findings, conclusions, or recommendations expressed in this material are those of the author(s) and do not necessarily reflect the views of the Under Secretary of Defense for Research and Engineering.

Authors' contributions E.A.B.E., D.J.C., J.C.A., conceived and supervised the study. Y.W.C. performed the simulations, analyzed the output. Y.W.C., D.J.C., J.C.A., and E.A.B.E contributed to the drafting and editing of the manuscript. All authors discussed the results and approved the final manuscript.

Availability of data and material All data needed to evaluate the conclusions in the paper are present in the paper. Additional data related to this paper may be requested from the authors.

Code availability All the codes are programmed by NCAR Command Language. The codes are available and maintained by Yeon-Woo Choi (choiyw@mit.edu).

\section{Declaration}

Conflicts of interest The authors declare no conflict of interest.

Open Access This article is licensed under a Creative Commons Attribution 4.0 International License, which permits use, sharing, adaptation, distribution and reproduction in any medium or format, as long as you give appropriate credit to the original author(s) and the source, provide a link to the Creative Commons licence, and indicate if changes were made. The images or other third party material in this article are included in the article's Creative Commons licence, unless indicated otherwise in a credit line to the material. If material is not included in the article's Creative Commons licence and your intended use is not permitted by statutory regulation or exceeds the permitted use, you will need to obtain permission directly from the copyright holder. To view a copy of this licence, visit http://creativecommons.org/licenses/by/4.0/.

\section{References}

Abatzoglou JT, Drobowski SZ, Parks SA, Hegewisch K (2018) TerraClimate, a high-resolution global dataset of monthly climate and climatic water balance from 1958-2015. Sci Data 5:170191

Ali A (1999) Climate change impacts and adaptation assessment in Bangladesh. Climate Res 12(2-3):109-116

Allen RG, Pereira LS, Raes D, Smith M (1998) Crop evapotranspiration-guidelines for computing crop water requirements. FAO Irrigation and Drainage Paper 56

Cannon AJ, Sobie SR, Murdock TQ (2015) Bias correction of GCM precipitation by quantile mapping: how well do methods preserve changes in quantiles and extremes? J Clim 28(17):6938-6959

Ciarlo JM, Coppola E, Fantini A et al (2020) A new spatially distributed added value index for regional climate models: the 
EURO-CORDEX and the CORDEX-CORE highest resolution ensembles. Climate Dynamics, 1-22.

CIESIN (2018) Gridded population of the world, version 4 (GPWv4): population density. Revision. https://doi.org/10.7927/H49C6VHW

Coffel ED, Horton RM, de Sherbinin A (2018) Temperature and humidity based projections of a rapid rise in global heat stress exposure during the 21st century. Environ Res Lett 13(1):014001

Dasgupta S, Huq M, Khan ZH, Ahmed MMZ, Mukherjee N, Khan MF, Pandey K (2014) Cyclones in a changing climate: the case of Bangladesh. Climate Dev 6(2):96-110

Ehret U, Zehe E, Wulfmeyer V, Warrach-Sagi K, Liebert J (2012) Should we apply bias correction to global and regional climate model data? Hydrol Earth Syst Sci Discuss 9:5355-5387

Flato G, Marotzke J, Abiodun B et al (2013) Evaluation of climate models. In: Climate change 2013: the physical science basis. Contribution of working group I to the fifth assessment report of the intergovernmental panel on climate change. Cambridge University Press, Cambridge, $\mathrm{p} 866$.

Foley JA, Prentice IC, Ramankutty N, Levis S, Pollard D, Sitch S, Haxeltine A (1996) An integrated biosphere model of land surface processes, terrestrial carbon balance, and vegetation dynamics. Global Biogeochem Cycles 10:603-628

Gettleman J (2017) More Than 1,000 Died in South Asia Floods This Summer. The New York Times. https://www.nytimes.com/2017/ 08/29/world/asia/floods-south-asiaindia-bangladesh-nepal-houst on.html.

Ghumman U, Horney J (2016) Characterizing the impact of extreme heat on mortality, Karachi, Pakistan, June 2015. Prehosp Disaster Med 31:263-266

Gianotti RL (2012) Regional climate modeling over the Maritime Continent: Convective cloud and rainfall processes. Ph.D. dissertation, Massachusetts Institute of Technology, pp 306

Gianotti RL, Eltahir EAB (2014a) Regional climate modeling over the Maritime Continent. Part I: new parameterization for convective cloud fraction. J Clim 27:1488-1503

Gianotti RL, Eltahir EAB (2014b) Regional climate modeling over the Maritime Continent. Part II: new parameterization for autoconversion of convective rainfall. J Clim 27:1504-1523

Giorgi F, Solmon F, Giuliani G (2016) Regional climatic model RegCM user's guide version 4.6. The Abdus Salam International Centre for Theoretical Physics Strada Costiera, Trieste

Gu HH, Wang GL, Yu ZB, Mei R (2012) Assessing future climate changes and extreme indicators in east and South Asia using the RegCM4 regional climate model. Clim Chang 114:301-317

Huq S (2001) Climate change and Bangladesh. Science 294:1617

Im ES, Eltahir EAB (2018) Simulation of the diurnal variation of rainfall over the western Maritime Continent using a regional climate model. Clim Dyn 51:73-88

Im ES, Gianotti RL, Eltahir EAB (2014) Improving the simulation of the West African Monsoon using the MIT regional climate model. J Clim 27(6):2209-2229

Im ES, Pal JS, Eltahir EAB (2017a) Deadly heat waves projected in the densely populated agricultural regions of South Asia. Sci Adv 3(8):e1603322

Im ES, Choi YW, Ahn JB (2017b) Worsening of heat stress due to global warming in South Korea based on multi-RCM ensemble projections. J Geophys Res: Atmos 122:11,444-11,461. https:// doi.org/10.1002/2017JD026731.

Im ES, Kang S, Eltahir EAB (2018) Projections of rising heat stress over the western Maritime Continent from dynamically downscaled climate simulations. Glob Planet Change 165:160-172. https://doi.org/10.1016/j.gloplacha.2018.02.014

IPCC (2013) Climate change 2013: the physical science basis. Contribution of working group I to the fifth assessment report of the intergovernmental panel on climate change. Cambridge University Press, Cambridge, New York, p 1535.
Kang S, Eltahir EAB (2018) North China Plain threatened by deadly heatwaves due to climate change and irrigation. Nat Commun 9:2894

Kang S, Im ES, Eltahir EAB (2019a) Future climate change enhances rainfall seasonality in a regional model of western Maritime Continent. Clim Dyn 52:747-764

Kang S, Pal JS, Eltahir EAB (2019b) Future heat stress during Muslim pilgrimage (Hajj) projected to exceed "extreme danger" levels. Geophys Res Lett 46(16):10094-10100

Khan TMA, Singh OP, Rahman MS (2000) Recent sea level and sea surface temperature trends along the Bangladesh Coast in relation to the frequency of intense cyclones. Mar Geod 23(2):103-116. https://doi.org/10.1080/01490410050030670

Kharin VV, Zwiers FW, Zhang X, Wehner M (2013) Changes in temperature and precipitation extremes in the CMIP5 ensemble. Clim Change 119:345-357

Kirtman B, Power SB, Adedoyin JA, Boer GJ, Bojariu R, Camilloni I, Doblas-Reyes FJ, Fiore AM, Kimoto M, Meehl GA, Prather M, Sarr A, Schär C, Sutton R, van Oldenborgh GJ, Vecchi G, Wang HJ (2013) Near-term climate change: projections and predictability. Climate change 2013: the physical science basis. Contribution of Working Group I to the Fifth Assessment Report of the Intergovernmental Panel on climate change. Cambridge University Press, Cambridge, pp 953-1028

Kreft S, Eckstein D, Melchior I (2017) Global climate risk index 2017: who suffers most from extreme weather events? weather-related loss events in 2015 and 1996 to 2015. https://germanwatch.org/ sites/germanwatch.org/files/publication/16411.pdf. Accessed 05 Dec 2020.

Liang X-Z, Kunkel KE, Meehl GA, Jones RG, Wang JXL (2008) Regional climate models downscaling analysis of general circulation models present climate biases propagation into future change projections. Geophys Res Lett 35:L08709

Marcella MP (2012) Biosphere-atmosphere interactions over semi-arid regions: Modeling the role of mineral aerosols and irrigation in the regional climate system. Ph.D. dissertation, Massachusetts Institute of Technology, p 282

Marcella MP, Eltahir EA (2012) Modeling the summertime climate of Southwest Asia: the role of land surface processes in shaping the climate of semiarid regions. J Clim 25(2):704-719

Marcella M, Eltahir EAB (2014) Introducing an irrigation scheme to a regional climate model: a case study over West Africa. J Clim 27:5708-5723

May W (2004) Potential future changes in the Indian summer monsoon due to greenhouse warming: analysis of mechanisms in a global time-slice experiment. Clim Dyn 22(4):389-414

Meehl GA, Tebaldi C (2004) More intense, more frequent, and longer lasting heat waves in the 21st century. Science 305(5686):994-997

MoEF (2009) Bangladesh Climate Change Strategy and Action Plan. Ministry of Environment and Forests, Government of the People's Republic of Bangladesh. http://cmsdata.iucn.org/downloads/bangl adesh_climate_change_strategy_and_action_plan_2009.pdf

Nissan H, Burkart K, Coughlan de Perez E, Van Aalst M, Mason S (2017) Defining and predicting heat waves in Bangladesh. J Appl Meteorol Climatol 56(10):2653-2670

OECD (2003) Development and climate change in Bangladesh: focus on coastal flooding and the Sundarbans. In: Agrawala S, Ota T, Ahmed AU (eds) Organization for economic co-operation and development (OECD) report, Paris, France. www.oecd.org/dataoecd/46/55/21055658.pdf. Accessed 25 Mar 2009

Pal JS, Eltahir EAB (2016) Future temperature in southwest Asia projected to exceed a threshold for human adaptability. Nat Clim Change 6:197-200

Pal JS, Giorgi F, Bi X et al (2007) Regional climate modeling for the developing world: the ICTP RegCM3 and RegCNET. Bull Am Meteorol Soc 88(9):1395-1409 
Piani C, Haerter JO, Coppola E (2010) Statistical bias correction for daily precipitation in regional climate models over Europe. Theor Appl Climatol 99(1-2):187-192

Qiu L, Im ES, Hur J, Shim KM (2020) Added value of very high resolution climate simulations over South Korea using WRF modeling system. Clim Dyn 54(1):173-189

Rahman MM, Islam MN, Ahmed AU, Georgi F (2012) Rainfall and temperature scenarios for Bangladesh for the middle of 21 st century using RegCM. J Earth Syst Sci 121:287-295. https://doi.org/ 10.1007/s12040-012-0159-9

Raymond C, Matthews T, Horton RM (2020) The emergence of heat and humidity too severe for human tolerance. Sci Adv 6(19):eaaw 1838

Reynolds RW, Rayner NA, Smith TM, Stokes DC, Wang WQ (2002) An improved in situ and satellite SST analysis for climate. J Clim 15:1609-1625

Seneviratne SI et al (2012) Chap 3: changes in climate extremes and their impacts on the natural physical environment. SREX. In: Field CB et al (eds) Special report on managing the risks of extreme events and disasters to advance climate change adaptation. Cambridge University Press, Cambridge, pp 109-230

Shahid S (2010) Recent trends in the climate of Bangladesh. Clim Res 42(3):185-193

Shahid S (2011) Trends in extreme rainfall events of Bangladesh. Theor Appl Climatol 104:489-499

Shahid S, Wang X-J, Harun SB et al (2016) Climate variability and changes in the major cities of Bangladesh: observations, possible impacts and adaptation. Reg Environ Change 16:459-471

Sherwood SC, Huber M (2010) An adaptability limit to climate change due to heat stress. Proc Natl Acad Sci 107(21):9552-9555

Sillmann J, Kharin V, Zwiers F et al (2013) Climate extremes indices in the CMIP5 multimodel ensemble: part 2. Future climate projections. J Geophys Res Atmos 118:2473-2493
Suh MS, Oh SG, Lee YS et al (2016) Projections of high resolution climate changes for South Korea using multiple-regional climate models based on four RCP scenarios. Part 1: surface air temperature. Asia-Pac J Atmos Sci 52(2):151-169

Switanek MB, Troch PA, Castro CL, Leuprecht A, Chang HI, Mukherjee R, Demaria E (2017) Scaled distribution mapping: a bias correction method that preserves raw climate model projected changes. Hydrol Earth Syst Sci 21(6):2649-2666

UN ESCAP (2015) Disasters in Asia and the Pacific: 2015 year in review. http://www.unescap.org/sites/default/files/2015_Year\% 20in\%20Review_final_PDF_1.pdf. Accessed 30 June 2020

Uppala S, Dee D, Kobayashi S, Berrisford P, Simmons A (2008) Towards a climate data assimilation system: status update of ERAinterim. ECMWF News1 115:12-18

Winter JM, Pal JS, Eltahir EAB (2009) Coupling of integrated biosphere simulator to regional climate model version 3. J Clim 22:2743-2757

World Bank (2013) Turn down the heat: climate extremes, regional impacts, and the case for resilience. In: A report for the World Bank by the Potsdam Institute for climate impact research and climate analytics. Washington, DC: World Bank. License: Creative Commons Attribution-NonCommercial-NoDerivatives3.0 Unported license (CC BY-NC-ND 3.0)

Zommers Z, van der Geest K, De Sherbinin A, Kienberger S, Roberts E, Harootunian G, Sitati A, James R (2016). Loss and damage: The role of ecosystem services.

Publisher's Note Springer Nature remains neutral with regard to jurisdictional claims in published maps and institutional affiliations. 